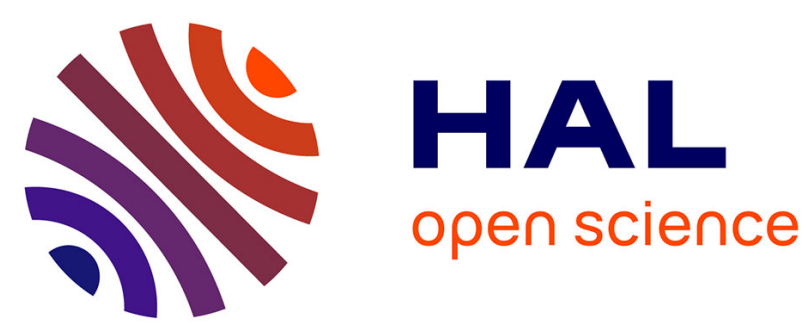

\title{
SANS response of VVER440-type weld material after neutron irradiation, post-irradiation annealing and reirradiation
}

\author{
Andreas Ulbricht, Frank Bergner, Juergen Boehmert, Matti Valo, \\ Marie-Helene Mathon, Andre Heinemann
}

\section{To cite this version:}

Andreas Ulbricht, Frank Bergner, Juergen Boehmert, Matti Valo, Marie-Helene Mathon, et al.. SANS response of VVER440-type weld material after neutron irradiation, post-irradiation annealing and reirradiation. Philosophical Magazine, 2007, 87 (12), pp.1855-1870. 10.1080/14786430601102999 . hal-00513810

\section{HAL Id: hal-00513810 \\ https://hal.science/hal-00513810}

Submitted on 1 Sep 2010

HAL is a multi-disciplinary open access archive for the deposit and dissemination of scientific research documents, whether they are published or not. The documents may come from teaching and research institutions in France or abroad, or from public or private research centers.
L'archive ouverte pluridisciplinaire HAL, est destinée au dépôt et à la diffusion de documents scientifiques de niveau recherche, publiés ou non, émanant des établissements d'enseignement et de recherche français ou étrangers, des laboratoires publics ou privés. 


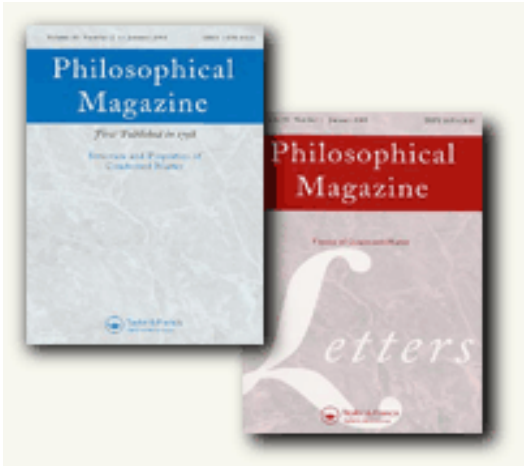

\section{SANS response of VVER440-type weld material after neutron irradiation, post-irradiation annealing and reirradiation}

\begin{tabular}{|r|l|}
\hline Journal: & Philosophical Magazine \& Philosophical Magazine Letters \\
\hline Manuscript ID: & TPHM-06-Mar-0056.R1 \\
\hline Journal Selection: & Philosophical Magazine \\
\hline Date Submitted by the & 03-Jul-2006 \\
\hline Complete List of Authors: & $\begin{array}{l}\text { Ulbricht, Andreas; Forschungszentrum Rossendorf, Institute of } \\
\text { Safety Research } \\
\text { Bergner, Frank; Forschungszentrum Rossendorf, Institute of Safety } \\
\text { Research } \\
\text { Boehmert, Juergen; Forschungszentrum Rossendorf, Institute of } \\
\text { Safety Research } \\
\text { Valo, Matti; VTT Industrial Systems } \\
\text { Mathon, Marie-Helene; CEA Saclay, Laboratoire Léon Brillouin } \\
\text { Heinemann, Andre; HMI Berlin, BENSC }\end{array}$ \\
\hline Keywords: & \begin{tabular}{l} 
annealing, embrittlement, neutron irradiation, SANS, steel \\
\hline Keywords (user supplied):
\end{tabular} \\
\hline
\end{tabular}

\section{(5) ScholaroNE \\ Manuscript Central}




\section{SANS response of VVER440-type weld material after neutron irradiation, post- irradiation annealing and reirradiation}

\section{A. ULBRICHT $\dagger$, F. BERGNER* $*$, J. BÖHMERT $\dagger$, M. VALO $\ddagger$, M.-H. MATHON§, A. HEINEMANNT}

$\dagger$ Forschungszentrum Rossendorf, P.O.B 510119, 01314 Dresden, Germany

‡ VTT Industrial Systems, P.O.B. 17042, 02044 VTT, Finland

$\S$ Laboratoire Léon Brillouin, CEA Saclay, 91191 Gif-sur-Yvette Cedex , France

If Hahn-Meitner-Institut Berlin, Glienicker Str. 100, 14109 Berlin, Germany

It is well accepted that the reirradiation behaviour of reactor pressure vessel (RPV) steel after annealing can be different from the original irradiation behaviour. We present the first small-angle neutron scattering (SANS) study of neutron irradiated, annealed and reirradiated VVER440type RPV weld material. The SANS results are analysed both in terms of the size distribution of irradiation-induced defect/solute atom clusters and in terms of the ratio of total and nuclear scattering intensity in a saturation magnetic field (A-ratio). The measured $A$-ratio is compared with calculations performed on the basis of the cluster composition reported for a similar weld material investigated by means of three-dimensional atom probe field ion microscopy. The observed deviation between both estimates and possible reasons for the discrepancy are discussed. Special emphasis is placed on the differences between the materials response to the original irradiation and to reirradiation after annealing. The results indicate that reirradiation-induced clusters are slightly different in their average composition and their formation saturates at a lower volume fraction than in the case of the original irradiation.

Keywords: SANS; Steel; Neutron irradiation; Embrittlement; Annealing

\section{Introduction}

Thermal annealing of embrittled reactor pressure vessel (RPV) steel and weld material is a well-known option for life extension of light water reactors [1]. In fact, large-scale annealing of the core belt region for the purpose of life extension was successfully applied in a number of cases including the first-generation VVER440type RPVs [1]. In the last three decades major scientific efforts have been focussed on the estimation of the temperature-time regime for optimum recovery of mechanical properties [2,3], a methodology for verification of the annealing effect (i.e. degree of reversal of irradiation hardening and embrittlement) using non-destructive techniques $[2,3]$ or small-specimen tests [3,4], and the phenomenological description of the reirradiation behaviour of RPV steels based on mechanical testing [3,5-7].

The phenomenological description of the reirradiation behaviour has been essentially founded on the dependence of the most important property change, i.e. the shift of the brittle-to-ductile transition temperature, on neutron fluence. If partial

*Corresponding author. Email: F.Bergner@fz-rossendorf.de 
recovery of the transition temperature is assumed as a result of annealing, the following three limiting cases can be identified: (1) The horizontal shift approach, according to which the reirradiation curve is obtained by a horizontal shift of the original curve (see figure 1a). (2) The vertical shift approach, according to which the reirradiation curve is obtained by a vertical shift of the original curve (see figure 1b). (3) The conservative approach based on a shift from the origin (see figure 1c). Additionally, an intermediate case between horizontal and vertical shift is depicted in figure 1d. The four cases will result in different margins for life extension. It is therefore desirable to have an approach capable of predicting the true reirradiation behaviour on a sound microstructural basis.

[Insert figure 1 about here]

However, mechanistic understanding of the materials response to neutron irradiation, post-irradiation annealing and reirradiation is still far from being satisfactory or even complete. Indirect conclusions about the mechanisms underlying the annealing and reirradiation response of RPV steels and welds have been drawn via analysing results of mechanical testing [6-8] and fractographic observations [9] of these materials. More direct evidence has been collected by means of quantitative TEM [9] and three-dimensional atom probe field ion microscopy (3DAP) [10]. In particular, it was shown that reirradiation-induced microstructural changes are different from the original irradiation response not only quantitatively but also in nature [10].

In the present paper results of small-angle neutron scattering (SANS) experiments performed for a VVER440-type weld material including three reirradiated conditions and a reirradiated and annealed condition are reported. In some contrast with TEM and state-of-the-art 3DAP, SANS measurements allow a statistically representative size distribution of irradiation-induced defect/solute atom clusters averaged over a macroscopic volume of some ten $\mathrm{mm}^{3}$ to be obtained. Furthermore, SANS is capable of providing some reduced information in terms of the $A$-ratio (see below) related to cluster composition including fractions of vacancies or self-interstitial atoms (SIA). On the other hand, 3DAP provides direct element-specific information on composition not accessible by means of SANS. Investigations of neutron irradiated and annealed RPV steels based on a combination of SANS and 3DAP were reported in the literature $[11,12]$. In particular, the cluster composition deduced by 3DAP was checked against SANS data in [12]. The discussion in the present work is essentially based on contrasting SANS results with those obtained by Pareige et al. [10] using 3DAP for similar VVER440-type weld material.

\section{Experiments}

The material investigated is VVER440-type weld material Sv10KhMFT of the composition given in table 1 in a total of seven different irradiation conditions summarized in table 2. Irradiations were carried out at surveillance positions of NPP Loviisa (Finland). Irradiation temperature was $270^{\circ} \mathrm{C}$. Specimens were provided by VTT Espoo (Finland) as slices of dimensions of $10 \mathrm{~mm}$ by $10 \mathrm{~mm}$ and thickness of $0.8 \mathrm{~mm}$. No additional surface preparation was needed for the SANS experiments.

[Insert table 1 about here]

[Insert table 2 about here] 
The SANS measurements were carried out at the PAXE spectrometer of the Orphee research reactor at LLB Saclay [13] and at the BENSC V4 spectrometer of HMI Berlin [14]. A neutron wavelength of $0.5 \mathrm{~nm}( \pm 10 \%)$ at half maximum was used. A beam diameter of $8 \mathrm{~mm}$ was realized by a Cd aperture fixed directly in front of the sample. The SANS intensity was measured with a 2-dimensional $64 \mathrm{~cm} \times 64$ $\mathrm{cm} \mathrm{BF}_{3}$-detector (LLB) or ${ }^{3} \mathrm{He}$-detector (HMI) at two different sample-detector distances of about $1 \mathrm{~m}$ and $4 \mathrm{~m}$ corresponding to a measuring range of the scattering vector of approximately $0.13 \mathrm{~nm}^{-1}$ to $2.9 \mathrm{~nm}^{-1}$. During the SANS measurements the samples were placed in a saturation magnetic field of $1.4 \mathrm{~T}$ perpendicular to the neutron beam direction. The scattering intensity was calibrated by direct determination of the intensity of the incident beam and the calibration was checked comparing the measuring results for a reference sample of known scattering cross section.

SANS data were processed by software routines of LLB and BENSC. In particular, the angular dependence of the scattered neutron intensity was utilized to separate the magnetic contribution from the total scattered intensity.

\section{Results}

The measured scattering cross section is composed of a coherent and an incoherent contribution. The incoherent contribution was eliminated assuming the scattering intensity to follow Porod's law (i.e. to be proportional to $Q^{-4}$ ) for large $Q$ values. After subtraction of the incoherent contribution the coherent scattering cross section is determined as shown in figure 2 for the unirradiated (U), the irradiated (I), and the irradiated and annealed (IA) conditions of the VVER440-type weld material. Irradiation clearly raises the nuclear and the magnetic contribution to the scattering cross section for $Q>0.8 \mathrm{~nm}^{-1}$ (see figure $2 \mathrm{~b}, \mathrm{c}$ ) in an analogous manner. Annealing reduces the effect to the initial level and gives rise to a small increase of the magnetic contribution in the $Q$ range from 0.5 to $0.8 \mathrm{~nm}^{-1}$ (see figure 2c).

\section{[Insert figure 2 about here]}

Further analysis is based on the indirect transformation method [15] and provides the volume distribution or the number density distribution of scatterers without assuming a certain type of distribution. According to our standard analysis we have assumed that the system consists of isolated scattering particles in a homogeneous matrix (two-phase approach), the particles are spherical and non-magnetic and the particle size is spatially uncorrelated. Multiple scattering is minimized by choosing a sufficiently small sample thickness on the expense of scattering intensity and measuring time.

The assumption of non-magnetic scatterers may be invalid in the case of significant fractions of $\mathrm{Fe}$ or $\mathrm{Ni}$ in clusters. The size distributions given in this paper were still valid on a relative scale in this case, but the absolute values of the volume fractions and number densities of scatterers would be incorrect. The issue is discussed in [12] but not solved completely. However, if the cluster composition is given, the size distribution of clusters can be calculated from the nuclear scattering cross section without any assumption on the magnetic character of the clustered atoms. 
The volume distribution of clusters obtained under the assumption of nonmagnetic scatterers is presented in figure 3. It exhibits the appearance typical of RPV steels: a broad distribution without a clear maximum in the size range up to $10 \mathrm{~nm}$ in the unirradiated condition and an additional sharp peak near a radius of $1 \mathrm{~nm}$ in the irradiated condition. Annealing reduces the volume fraction corresponding to the peak position to the initial level. Simultaneously, a new smaller peak centred at about $3 \mathrm{~nm}$ of radius appears. These effects can be traced back to the scattering curves (see figure $2 \mathrm{c}$ ).

\section{[Insert figure 3 about here]}

The same procedure applied to the reirradiated samples yields the results depicted in figures 4 and 5. We have observed that: (1) There is a reirradiation-induced increase of the volume fraction of scatterers in the size range around $1 \mathrm{~nm}$ of radius as for the original irradiation. (2) The increase due to reirradiation is smaller than due to the original irradiation. (3) The increase saturates at a neutron fluence corresponding to condition IAI-2. (4) The volume fraction of scatterers formed in the size range around $3 \mathrm{~nm}$ as a result of annealing remains unchanged. (5) Annealing of the reirradiated material in turn results in a reduction of the volume fraction around $1 \mathrm{~nm}$ of radius and a slight increase of the volume fraction of scatterers in the size range around $3 \mathrm{~nm}$.

[Insert figure 4 about here] [Insert figure 5 about here]

The above observations suggest the distinction of two particle size ranges: The first one from $0.5 \mathrm{~nm}$ (lower detection limit of SANS for commercial Fe-based alloys) to about $2.5 \mathrm{~nm}$ essentially applies to the irradiation or reirradiation response. The second range from about $2.5 \mathrm{~nm}$ to $4.5 \mathrm{~nm}$ is important for the annealing response after irradiation or reirradiation. The total volume fractions, $c$, of scatterers related to these size ranges and measured values of Vickers hardness, HV10, are listed in table 3 for each of the conditions investigated.

[Insert table 3 about here]

The $A$-ratio is defined as ratio of the SANS cross sections perpendicular and parallel to the direction of the applied saturation magnetic field and can be expressed as the ratio of the total SANS cross section and the nuclear cross section. The $A$-ratio can also be calculated after Fourier transformation, i.e. in the size space. As in the case of the volume fraction of irradiation-induced clusters, the $A$-ratio was estimated by integrating the respective size distributions over either size range $(0.5$ to $2.5 \mathrm{~nm}$ and 2.5 to $4.5 \mathrm{~nm}$ ) separately. The estimated values of the $A$-ratio are compiled in table 4 along with the irradiation-induced increase of the volume fraction of scatterers and the irradiation-induced hardness increase. In table 4 the unirradiated condition, $U$, is taken as reference for conditions I and IA, whereas the irradiated and annealed condition, IA, is taken as reference for conditions IAI-1, IAI-2, IAI-3 and IAI-3A. Of course, the $A$-ratio can only be calculated provided that a significant volume fraction of scatterers has formed.

[Insert table 4 about here] 


\section{Discussion}

\subsection{Original irradiation response}

4.1.1. Magnetic scattering. Analysis of the measured SANS data is limited by the fact that the detailed composition of the detected irradiation-induced clusters is generally unknown. On the other hand, one has the freedom to start either from the nuclear scattering cross section or from the magnetic cross section. Of the needed assumptions about the nuclear or magnetic scattering length of the clusters, the one about the magnetic scattering length is less restricting under the present conditions. Indeed, the assumption of non-magnetic scatterers is absolutely valid in the case of pure $\mathrm{Cu}$ clusters or pure vacancy clusters and the magnetic contrast is maximum. If the clusters contain $\mathrm{Fe}$ atoms, the magnetic contrast may be reduced with the amount of reduction depending on the magnetic moment of the Fe atoms in the cluster. If we assume the addition of 50 at. $-\% \mathrm{Fe}$ of the same magnetic scattering length as matrix $\mathrm{Fe}$, the magnetic contrast will be reduced by a factor of 4 . Therefore, the true volume fractions may be up to about four times (but not orders of magnitude) larger than those specified in figures 3 and 5 and tables 3 and 4.

The above estimation shows that the major observations of the present investigation, namely the formation of irradiation-induced clusters in the size range from 0.5 to $2.5 \mathrm{~nm}$ (radius), the disappearance of these clusters after annealing accompanied by the appearance of scatterers in the size range from 2.5 to $4.5 \mathrm{~nm}$, and the appearance of reirradiation-induced clusters in the former size range, hold true. The calculated volume fractions are minimum values.

4.1.2. A-ratio. A more detailed discussion of the present results depends on the knowledge about the composition of the scatterers. However, the composition of the detected irradiation-induced clusters cannot be inferred from SANS measurements alone. On the other hand, any candidate composition can be checked for consistency by comparing calculated and measured values of the $A$-ratio [12]. Cluster compositions observed by means of 3DAP are reported in [10] for similar VVER440type weld material $(0.16 \mathrm{wt} .-\% \mathrm{Cu})$ irradiated under similar conditions summarized in table 5. These clusters are characterized as coherent $\mathrm{Cu}-\mathrm{Si}-\mathrm{Mn}-\mathrm{Ni}-\mathrm{P}$-enriched clusters of about $2 \mathrm{~nm}$ in diameter and of a number density of $5 \times 10^{23} \mathrm{~m}^{-3}$ [10].

[Insert table 5 about here]

In order to check for consistency of the typical compositions reported in [10] with the $A$-ratios obtained in the present case, a theoretical $A$-ratio was calculated according to equations (1)-(3).

$$
A=1+\left(\frac{\sum_{i} n_{i}^{\text {Cluster }} b_{\text {mag }, i}^{\text {Cluster }}-\sum_{i} n_{i}^{\text {Matrix }} b_{\text {mag }, i}^{\text {Matrix }}}{\sum_{i} n_{i}^{\text {Cluster }} b_{n u c, i}^{\text {Cluster }}-\sum_{i} n_{i}^{\text {Matrix }} b_{\text {nuc }, i}^{\text {Matrix }}}\right)^{2}
$$

In equation (1), $b$ and $n$ refer to scattering length and atomic fraction, respectively, subscripts nuc and mag refer to nuclear and magnetic scattering length, respectively, 
and summation is performed over all types of atoms constituting cluster or matrix. If we restrict ourselves to the species the clusters are enriched with [10], ignore strain fields, assume the matrix to be pure Fe and assume the magnetic moments of Fe and $\mathrm{Ni}$ in the clusters to be the same as in the matrix, equation (1) is simplified to

$$
A=1+\left(\frac{6.0\left(n_{F e}-1\right)+1.0 n_{N i}}{9.45\left(n_{F e}-1\right)+10.3 n_{N i}+7.72 n_{C u}-3.75 n_{M n}+4.15 n_{S i}+5.13 n_{P}}\right)^{2}
$$

where the coefficients in the nominator are the values in units of $\mathrm{fm}\left(10^{-15} \mathrm{~m}\right)$ of the magnetic scattering length for $\mathrm{Fe}$ and $\mathrm{Ni}$ [16], the coefficients in the denominator are the values in units of fm of the nuclear scattering length for $\mathrm{Fe}, \mathrm{Ni}, \mathrm{Cu}, \mathrm{Mn}, \mathrm{Si}$, and $\mathrm{P}$ [17], and where

$$
n_{F e}+n_{N i}+n_{C u}+n_{M n}+n_{S i}+n_{P}=1
$$

in the case of vacancy-free clusters. In the case of clusters containing a vacancy fraction, $n_{\mathrm{vac}}$, the concentrations in equation (3) have to be rescaled according to equation (4):

$$
n_{F e}+n_{N i}+n_{C u}+n_{M n}+n_{S i}+n_{P}=1-n_{v a c}
$$

The cluster compositions reported in [10] and the $A$-ratios calculated assuming vacancy-free clusters of the reported composition are summarized in table 6.

[Insert table 6 about here]

We find the measured $A$-ratio of the irradiation-induced clusters $(1.6 \pm 0.1)$ to be significantly smaller than the calculated ones (3.85 and 7.90). The deviation in case of the composition reported for clusters located at dislocations (7.90) is larger than for clusters located in the matrix (3.85). It may be noticed that the discrepancy would even be more significant in both cases, if the magnetic scattering length per $\mathrm{Fe}$ or $\mathrm{Ni}$ atom for the cluster were smaller than for the matrix. There are several possible reasons for the observed discrepancy:

(1) Clusters characterized in [10] may contain a significant fraction of vacancies not detected by means of 3DAP. Assuming a vacancy fraction, $n_{\mathrm{vac}}=0.46$, in the clusters while keeping all other elements in the reported proportion will reduce the $A$ ratio from 3.85 (for the case of cluster located in the matrix, see table 6) to the observed level of 1.6. Evidence for the contribution of vacancies to $\mathrm{Cu}$-vacancy clusters is reported in [18] for Fe-Cu model alloys. The presence of small clusters containing 4 to 6 vacancies in neutron irradiated VVER440-type weld material was concluded from positron lifetime measurements [19].

(2) Mn would have an even stronger effect than vacancies because of its negative nuclear scattering length, but there is certainly no doubt about the level of $\mathrm{Mn}$ reported in [10]. However, taking the reported upper limit instead of the mean value will reduce the $A$-ratio from 3.85 to 3.36 . Properly varying the levels of the other elements within the error range gives rise to an additional maximum reduction of the A-ratio up to about 3 but not to the observed level of 1.6.

(3) There may exist a second population of irradiation-induced features of different nature. Nanovoids and self-interstitial atom (SIA) clusters, which are not 
detectable by 3DAP in complex commercial alloys [10], are candidates. In fact, both pure nanovoids and pure SIA clusters would give an $A$-ratio of 1.4 (equations (2) and (4)) thus allowing for an average $A$-ratio of 1.6. Evidence for the contribution of SIA clusters (loops) is reported in [9] for VVER440-type weld material.

(4) Strain fields are reported to decrease the $A$-ratio in the case of $\mathrm{Fe}-\mathrm{Cu}$ clusters [13]. Coherency strain induced by atom size misfit is supposed to be too small to explain the observed deviations in the present case, especially if the clusters contain vacancies, which are expected to compensate for the atom size misfit at least partly.

4.1.3. Nuclear scattering. Our standard analysis is based on the magnetic scattering cross section, because in most cases the cluster composition is not known in advance. However, if the cluster composition is given, the size distribution of scatterers (and related quantities) can be calculated from the nuclear scattering cross section without any assumption about the magnetic character of the scatterers. For the present weld material in the irradiated condition, the estimated total volume fraction of irradiationinduced scatterers in the size range from 0.5 to $2.5 \mathrm{~nm}$ is 4 vol.- $\%$, if the estimation is based on the reference composition for clusters in the matrix (see table 6). It is 5 vol.- $\%$, if the calculation is based on the composition for clusters at dislocations (see table 6). These values are 40 to 50 times larger than the estimate obtained from the magnetic cross section assuming non-magnetic scatterers (see table 4). With reported $\mathrm{Cu}$ fractions in the clusters between 20 and 35 at.-\% (see table 6), a minimum $\mathrm{Cu}$ content of the weld material of 0.80 at. $-\%$ or 0.91 wt. $-\%$ would be necessary to obtain a volume fraction as high as 4 vol.- $\%$ of coherent clusters. Clearly, this is contrary to the actual $\mathrm{Cu}$ content of 0.14 wt.- $\%$ (see table 1 ).

This discrepancy cannot be fully resolved by taking into account measuring errors and marginal differences in the materials or irradiation conditions. The possible reasons of the deviation are similar as discussed above. In particular, a vacancy fraction, $n_{\mathrm{vac}}=0.46$, in the clusters along with the other solute atoms in the reported proportion (see table 6, matrix) would give a calculated $A$-ratio of 1.6 (equations (2) and (4)), which is in agreement with the measured $A$-ratio, and simultaneously a volume fraction of clusters of 0.24 vol.- $\%$, which is also reasonable in the following respects:

(1) The value of 0.24 vol.- $\%$ does not conflict with the total $\mathrm{Cu}$ content of the weld material of 0.14 wt.- $\%$ or 0.12 at.-\%. In fact, even the maximum estimate of the $\mathrm{Cu}$ fraction in clusters $\left(1-n_{\mathrm{vac}}\right) \times 35$ at. $-\%=19$ at.- $\%$ requires only about 0.05 at. $-\%$ $\mathrm{Cu}$. The balance of at least 0.07 at. $-\%$ consists of matrix $\mathrm{Cu},(0.05 \pm 0.02)$ at.- $\%$ according to [10], and $\mathrm{Cu}$ in clusters of radius smaller than $0.5 \mathrm{~nm}$, i.e. below the detection limit of SANS.

(2) The value of 0.24 vol.- $\%$ compares well with the cluster fraction of 0.25 vol. $-\%$ calculated from the reported estimate of the number density of clusters, $N=5 \times 10^{23} \mathrm{~m}^{-3}$, in the similar weld material [10].

(3) Finally, the value of 0.24 vol.- $\%$ is also consistent with the fraction of 0.17 vol. $-\%$ one would calculate from the magnetic scattering cross section assuming the same cluster composition as above $(46 \%$ vacancies plus solute atoms in the proportion according to table 6) and the same magnetic scattering length of the $\mathrm{Fe}$ atoms in the cluster as in the matrix.

Therefore, it seems to be reasonable to assume an average vacancy fraction, $n_{\text {vac }}=0.46$, and an average total fraction of atoms, $n_{\text {tot }}=0.54$, in the clusters, the latter partitioned in the proportion according to table 6. However, SANS is a volumeintegrating method and it cannot be decided, whether all clusters have about the same 
composition, or there is a broad spectrum of compositions, or there are two types of clusters of essentially different composition. In particular, it is possible that the estimated vacancy fraction forms nanovoids not detectable by 3DAP and the remaining atom fraction forms clusters of the composition deduced from the 3DAP measurements. The monomodal distribution of irradiation-induced clusters observed in the present work, the monomodal distributions observed after stepwise annealings of other RPV steels [20], and the observed Arrhenius-like annealing behaviour [20] seem to be in contrast with the latter variant.

In the case of a unique type of defect/solute clusters, defects of the SIA type are energetically unfavourable because of large elastic strains resulting in combination with oversize $\mathrm{Cu}$ atoms. In the case of two distinct types of defects, it is possible that the second population is SIA clusters instead of nanovoids discussed above. However, planar SIA clusters (loops) are characterized by a much weaker contrast [21] than spherical nanovoids and a much larger number density of SIA clusters, $N \square 10^{25} \mathrm{~m}^{-3}$, would therefore be necessary to account for the observed SANS cross sections. This estimate strongly conflicts with the values of about $2 \times 10^{21} \mathrm{~m}^{-3}$ and $5 \times 10^{21} \mathrm{~m}^{-3}$ reported in [19] and [9], respectively, on the basis of TEM observations of similar VVER440-type weld material irradiated to even higher neutron fluences. The relevant conclusion is that SIA loops are not ruled out by the present SANS experiments, but they do not contribute significantly to the irradiation-induced increase of the SANS cross section. The situation essentially changes, if SIA clusters are decorated (e.g. with undersize Mn atoms), but this type of clusters was not reported in [10].

4.1.4. Hardness. The observed significant hardness increase (see table 4) is related to the formation of irradiation-induced clusters via the interaction of these clusters with dislocations. The hardness increase confirms the physical significance of the conclusions drawn about the formation of irradiation-induced clusters.

\subsection{Annealing response}

Annealing is accompanied by the disappearance of the irradiation-induced volume fraction of clusters in the size range from 0.5 to $2.5 \mathrm{~nm}$ and the formation of a smaller fraction in the size range from 2.5 to $4.5 \mathrm{~nm}$. The high $A$-ratio $(A \square 10)$ indicates that the scatterers observed after annealing are $\mathrm{Cu}$-rich precipitates. This is in agreement with the conclusion inferred by Pareige et al. [10] from the reported 3DAP observations after reirradiation [10]. The $\mathrm{Cu}$-rich precipitates are still coherent with the Fe matrix.

It is interesting to note that, in contrast with the above observation for weld material $(0.14$ wt.-\% Cu), significant annealing-induced cluster growth (or coarsening) is not observed in RPV base material with $\mathrm{Cu}$ contents less than $0.2 \mathrm{wt}$.$\%$ at an annealing temperature of $475^{\circ} \mathrm{C}[20,22,23]$. A possible explanation for this difference is the lower carbon content in the weld.

The assumption of non-magnetic scatterers is justified in the case of $\mathrm{Cu}$-rich precipitates. Therefore, the volume fraction of $0.026 \%$ (see table 4 ) obtained from the magnetic scattering cross section is valid. This value is smaller by a factor of 4 to 10 than the volume fraction of $0.1 \%$ to $0.24 \%$ (depending on the underlying assumptions, see above) of irradiation-induced clusters in the size range from 0.5 to $2.5 \mathrm{~nm}$ before annealing. A similar behaviour was observed before by means of 3DAP for a French 
CHOOZ RPV steel [24]. It is interesting to notice that the estimated volume fractions before and after annealing roughly correspond to the same amount of $\mathrm{Cu}$.

The irradiation-induced hardness increase is almost completely reversed by annealing (see table 4). This is in agreement with both the dissolution of a substantial fraction of irradiation-induced clusters in the size range from 0.5 to $2.5 \mathrm{~nm}$ responsible for the original hardness increase and a lower hardening capacity of the smaller fraction of $\mathrm{Cu}$ precipitates in the size range from 2.5 to $4.5 \mathrm{~nm}$ formed during annealing.

\subsection{Reirradiation response}

The basic observation from the SANS experiments for the reirradiated specimens (conditions IAI-1, IAI-2 and IAI-3) is that clusters are formed in the same size range and with a similar distribution as in the case of the original irradiation (condition I). These clusters are characterized by a slightly higher $A$-ratio than for the original irradiation and the $A$-ratio further increases with increasing neutron fluence (see table 4). Furthermore, as the agreement of the volume fractions for conditions IAI-2 and IAI-3 shows, the formation of reirradiation-induced clusters observed by SANS strongly decelerates or even saturates in the fluence range near or below the fluence corresponding to condition IAI-2. Provided the magnetic character of the reirradiation-induced clusters and the clusters formed during the original irradiation is about the same the maximum value of the volume fraction is only half as high as the volume fraction observed after the original irradiation. No significant reirradiationinduced changes in the size range larger than $2.5 \mathrm{~nm}$ are observed.

To start with the common features (coinciding size ranges, similar $A$-ratios) it can be assumed that the reirradiation-induced clusters are not completely different in composition from the clusters present after the original irradiation. The observation reported in [10], namely that no $\mathrm{Cu}-\mathrm{Si}-\mathrm{Mn}-\mathrm{Ni}-\mathrm{P}-$-enriched clusters could be detected for the reirradiated condition, may be partly attributed to the relatively low neutron fluence (see table 5).

In order to discuss the differences, we have to ask, in which details does the starting point for the reirradiation differ from the starting point for the original irradiation. Two such details have been identified: (1) There are coherent $\mathrm{Cu}$-rich precipitates in the size range from 2.5 to $4.5 \mathrm{~nm}$, which were not present at the beginning of the original irradiation. (2) As a consequence, the concentration of matrix $\mathrm{Cu}$ must be lower than prior to the original irradiation. Taking into account the total $\mathrm{Cu}$ content of the material $(0.12$ at.- $\%)$ and the volume fraction of $\mathrm{Cu}$-rich precipitates after annealing $(0.026$ vol.- $\%)$ the matrix concentration of $\mathrm{Cu}$ is estimated to be lower than about 0.1 at.- $\%$. In addition, after annealing there may be remnants of the dissolved clusters at sizes well below the detection limit of SANS of about $0.5 \mathrm{~nm}$ (radius), which were also not present after the original irradiation.

On the one hand, the reduced concentration of matrix $\mathrm{Cu}$ after annealing is consistent with the fact that the maximum volume fraction of reirradiation-induced clusters is significantly less than after the original irradiation. On the other hand, the reduced matrix $\mathrm{Cu}$ concentration does not explain the increased $A$-ratio. On the contrary, the expected decrease of the $\mathrm{Cu}$ fraction in the clusters would reduce, not raise, the $A$-ratio.

The resolution of the latter discrepancy must be left for future work. However, any reduction of the average vacancy fraction in the reirradiation-induced clusters 
relative to the original irradiation would explain an increase of the $A$-ratio. A reduced vacancy fraction can be the result of a decrease of the steady-state matrix concentration of vacancies due to the operation of additional sinks, such as the observed $\mathrm{Cu}$-rich precipitates in the size range from 2.5 to $4.5 \mathrm{~nm}$. In fact, there is evidence that coherent precipitates of oversize $\mathrm{Cu}$ atoms in Fe attract vacancies [25].

A consistent estimation of the partition of 0.12 at.- $\% \mathrm{Cu}$ onto defects of different size is summarized below for the reirradiated condition IAI-3: (1) About 0.026 at. $-\% \mathrm{Cu}$ is bound in $\mathrm{Cu}$-rich precipitates in the size range from 2.5 to $4.5 \mathrm{~nm}$. (2) The $\mathrm{Cu}$ fraction contributing to clusters in the size range from 0.5 to $2.5 \mathrm{~nm}$ is half that for condition I, i.e. 0.025 at.- $\%$, if the compositions are assumed to be equal, or slightly higher, if a smaller vacancy fraction is assumed than for condition I. (3) Matrix $\mathrm{Cu}$ amounts to about 0.05 at.-\% according to [10]. (4) The balance $\mathrm{Cu}$ is bound in clusters smaller than $0.5 \mathrm{~nm}$ in radius.

Regarding hardness, the basic observation is a reirradiation-induced increase to about the same level as that observed after the original irradiation. What would be expected is an increase proportional to the square root of cluster volume fraction, in particular:

$$
H_{i}=H_{u}+a \sqrt{\Delta c}
$$

for linear superposition or

$$
H_{i}=\sqrt{H_{u}^{2}+b^{2} \Delta c}
$$

for quadratic superposition. In equations (5)-(6), $H_{\mathrm{i}}$ and $H_{\mathrm{u}}$ are the Vickers hardness values for the irradiated and unirradiated condition, respectively, and $\Delta c$ is the total volume fraction of irradiation- (or reirradiation-) induced clusters. $a$ and $b$ are coefficients related to obstacle strength and accounting for the units. If $H_{\mathrm{i}}$ and $H_{\mathrm{u}}$ are measured in common units (see table 3 ) and $\Delta c$ is expressed as a fractional quantity (instead of vol.- $\%$ as in table 4), the values, $a=970$ and $b=3700$, are obtained for the original irradiation. Applying the same values to the reirradiation behaviour (condition IAI-3), estimates of the hardness value, $H_{\mathrm{i}}=233$ and $H_{\mathrm{i}}=227$, are obtained for linear and quadratic superposition, respectively. These values have to be compared with the hardness value measured for condition IAI-3, $H_{\mathrm{i}}=241$. The higher value of the measured hardness indicates a higher obstacle strength of reirradiationinduced clusters as compared with the original irradiation. The conclusion of different obstacle strengths is consistent with differing values of the $A$-ratio for the original irradiation and reirradiation.

As in the case of the first annealing (condition IA) the reirradiation-induced hardness increase is essentially reversed by annealing (see table 4). However, the reversal seems to be incomplete.

\section{Conclusions}

Irradiation-induced clusters in VVER440-type weld material are observed by SANS and contrasted with previous 3DAP measurements for similar weld material [10]. There is a discrepancy between the $A$-ratios measured by SANS and calculated on the 
basis of the reported composition. The conflict can be removed, if the average cluster is assumed to contain vacancies not detected by 3DAP.

Thermal annealing at $475^{\circ} \mathrm{C} / 100 \mathrm{~h}$ results in complete disappearance of irradiation-induced clusters in the size range from 0.5 to $2.5 \mathrm{~nm}$ accompanied by a reversal of the irradiation-induced hardness increase and in the formation of scatterers of radii between 2.5 and $4.5 \mathrm{~nm}$. Because of their high $A$-ratio $(A \square 10)$ these scatterers are identified as $\mathrm{Cu}$-rich precipitates.

As a result of reirradiation after annealing, clusters are formed in the same size range $(0.5-2.5 \mathrm{~nm})$ as for the original irradiation but their formation strongly decelerates or saturates at a smaller volume fraction. The new average cluster differs in composition from the original one.

The observed hardness change due to reirradiation indicates that the obstacle strength of the reirradiation-induced clusters is higher than that for the original irradiation.

Thermal annealing after reirradiation results in partial disappearance of irradiation-induced clusters in the size range from 0.5 to $2.5 \mathrm{~nm}$ and partial reversal of the irradiation-induced hardness increase.

\section{References}

[1] T. Planman, R. Pelli, K. Törrönen, Irradiation embrittlement mitigation, AMES Report No. 1, EUR 16072 EN, (European Commission, 1995).

[2] K. Popp, G. Brauer, W.-D. Leonhardt, et al., in Radiation Embrittlement of Nuclear Reactor Pressure Vessel Steels: An International Review, ASTM STP 1011, edited by L.E. Steele, (American Society for Testing and Materials, Philadelphia, 1989), pp. 188-205.

[3] R. Pelli, K. Törrönen, State of the art review on thermal annealing, AMES Report No. 2, EUR 16278 EN, (European Commission, 1995).

[4] A. Kryukov, P. Platonov, Ya. Shtrombakh, et al., Nucl. Engng. Design 16059 (1996).

[5] A.D. Amayev, A.M. Kryukov, M.A. Sokolov, in: Radiation Embrittlement of Nuclear Reactor Pressure Vessel Steels: An International Review, ASTM STP 1170, edited by L.E. Steele, (American Society for Testing and Materials, Philadelphia, 1993), pp. 369-379.

[6] J. Kohopää, R. Ahlstrand, Int. J. of Pressure Vessels and Piping 77575 (2000).

[7] Ya.I. Shtrombakh, Int. J. of Pressure Vessels and Piping 77585 (2000).

[8] R. Chaouadi, R. Gerard, J. Nucl. Mater. 34565 (2005).

[9] B.A. Gurovich, E.A. Kuleshova, O.V. Lavrenchuk, et al., J. Nucl. Mater. 264 333 (1999).

[10] P. Pareige, B. Radiguet, R. Krummeich-Brangier, et al., Phil. Mag. 85429 (2005).

[11] P. Pareige, P. Auger, S. Welzel, et al., in: Effects of Radiation on Materials: 19th Int. Symp., ASTM STP 1366, edited by M.L. Hamilton, A.S. Kumar, S.T. Rosinski, M.L. Grossbeck, (American Society for Testing and Materials, West Conhohocken, 2000), pp. 435-447.

[12] R.G. Carter, N. Soneda, K. Dohi, et al., J. Nucl. Mater. 298211 (2001).

[13] M.H. Mathon, A. Barbu, F. Dunstetter, et al., J. Nucl. Mater. 245224 (1997).

[14] U. Keiderling, A. Wiedenmann, Physica B 213\&214 895 (1995).

[15] O. Glatter, J. Appl. Cryst. 137 (1980). 
[16] G. Kostorz, in Physical Metallurgy, edited by R.W. Cahn and P. Haasen, (North-Holland, Amsterdam, 1996), Vol. 2, pp. 1115-1199.

[17] L. Koester, H. Rauch, E. Seymann, At. Data Nucl. Data Tabl. 4965 (1991).

[18] Y. Nagai, Z. Tang, M. Hassegawa, et al., Phys. Rev. B 63134110 (2001).

[19] J. Kocik, E. Keilova, J. Cizek, et al., J. Nicl. Mater. 30352 (2002).

[20] A. Ulbricht, F. Bergner, C. Dewhurst, et al., J. Nucl. Mater. 35327 (2006).

[21] A. Seeger, M. Rühle, Ann. Physik 11216 (1963).

[22] J. Böhmert, H.-W. Viehrig, A. Ulbricht, J. Nucl. Mater. 297251 (2001).

[23] A. Ulbricht, PhD Thesis, TU Bergakademie Freiberg, Germany, 2006.

[24] P. Auger, P. Pareige, S. Welzel, J-C. Van Duysen, J. Nucl. Mater. 280331 (2000).

[25] A. Takahashi, N. Soneda, S. Ishino, et al., Phys. Rev. B 67024104 (2003). 
Table 1. Composition of VVER440-type Sv10KhMFT weld material (wt.-\%).

$\begin{array}{lllllllllll}\mathrm{C} & \mathrm{Mn} & \mathrm{Si} & \mathrm{Cr} & \mathrm{Ni} & \mathrm{Mo} & \mathrm{V} & \mathrm{S} & \mathrm{P} & \mathrm{Cu} & \mathrm{Co} \\ 0.06 & 1.14 & 0.40 & 1.63 & 0.11 & 0.48 & 0.20 & 0.016 & 0.035 & 0.14 & 0.010\end{array}$


Table 2. Conditions of the samples for SANS experiments with $\Phi$ and $\varphi$ denoting neutron fluence and flux for neutron energies, $E>1 \mathrm{MeV}$ (to obtain values for neutron energies, $E>0.5 \mathrm{MeV}$, roughly multiply by 1.4 ).

\section{Designation Details}

$\mathrm{U}$

I

unirradiated

IA

irradiated $\left(\Phi=2.5 \cdot 10^{19} \mathrm{~cm}^{-2}, \varphi=3.0 \cdot 10^{11} \mathrm{~cm}^{-2} \mathrm{~s}^{-1}\right)$

IAI-1

annealed $\left(475{ }^{\circ} \mathrm{C} / 100 \mathrm{~h}\right)$ after irradiation

IAI-2

reirradiated $\left(\Phi=0.9 \cdot 10^{19} \mathrm{~cm}^{-2}, \varphi=3.0 \cdot 10^{11} \mathrm{~cm}^{-2} \mathrm{~s}^{-1}\right)$

IAI-3

IAI-3A

reirradiated $\left(\Phi=1.8 \cdot 10^{19} \mathrm{~cm}^{-2}, \varphi=3.0 \cdot 10^{11} \mathrm{~cm}^{-2} \mathrm{~s}^{-1}\right)$ reirradiated $\left(\Phi=2.7 \cdot 10^{19} \mathrm{~cm}^{-2}, \varphi=3.0 \cdot 10^{11} \mathrm{~cm}^{-2} \mathrm{~s}^{-1}\right)$ annealed $\left(475^{\circ} \mathrm{C} / 100 \mathrm{~h}\right)$ after reirradiation 3 

3 4

Table 3. Measured total volume fraction, $c$, of non-magnetic structural defects in the size ranges specified and Vickers hardness, HV10, at load $98.1 \mathrm{~N}$.

Condition Volume fraction in specified size range, $c /$ vol.- $\% *$ $0.5-2.5 \mathrm{~nm} \quad 2.5-4.5 \mathrm{~nm}$

$\begin{array}{llll}\mathrm{U} & 0.057 & 0.073 & 210\end{array}$

$\begin{array}{llll}\text { I } & 0.158 & 0.062 & 241\end{array}$

$\begin{array}{llll}\text { IA } & 0.051 & 0.099 & 212\end{array}$

$\begin{array}{llll}\text { IAI-1 } & 0.067 & 0.110 & 236\end{array}$

$\begin{array}{llll}\text { IAI-2 } & 0.095 & 0.101 & 235\end{array}$

$\begin{array}{llll}\text { IAI-3 } & 0.098 & 0.107 & 241\end{array}$

$\begin{array}{llll}\text { IAI-3A } & 0.065 & 0.114 & 221\end{array}$

* typical error: 0.005

$\dagger$ mean value of 10 measurements, typical standard deviation: 5 
Table 4. Volume fraction, $\Delta c$, and $A$-ratio of irradiation-induced clusters and irradiation-induced hardness increase. For calculation of $\Delta c$, clusters are assumed to be non-magnetic.

\begin{tabular}{|c|c|c|c|c|c|c|}
\hline \multirow[t]{2}{*}{ Condition } & \multirow[t]{2}{*}{ Reference } & \multicolumn{2}{|c|}{$\begin{array}{l}\text { Volume fraction in specified } \\
\text { size range, } \Delta c \text { / vol.- } \%\end{array}$} & \multicolumn{2}{|c|}{$A$-ratio } & \multirow[t]{2}{*}{$\begin{array}{l}\text { Hardness increase } \\
\Delta \mathrm{HV} 10\end{array}$} \\
\hline & & $0.5-2.5 \mathrm{~nm}$ & $2.5-4.5 \mathrm{~nm}$ & $0.5-2.5 \mathrm{~nm}$ & $2.5-4.5 \mathrm{~nm}$ & \\
\hline I & $\mathrm{U}$ & 0.102 & 0 & 1.56 & - & 31 \\
\hline IA & $\mathrm{U}$ & 0 & 0.026 & - & $\square 10$ & 2 \\
\hline IAI-1 & IA & 0.016 & 0.011 & 1.74 & - & 24 \\
\hline IAI-2 & IA & 0.044 & 0.002 & 1.88 & - & 23 \\
\hline IAI-3 & IA & 0.047 & 0.008 & 2.09 & - & 29 \\
\hline IAI-3A & IA & 0.014 & 0.015 & - & $\square 10$ & 9 \\
\hline \multicolumn{2}{|c|}{ Typical error: } & 0.007 & 0.007 & 0.1 & & 7 \\
\hline
\end{tabular}


Table 5. Irradiation, annealing and reirradiation conditions according to [10] for neutron energies, $E>0.5 \mathrm{MeV}$.

\section{Designation Details}

I irradiated, $\Phi=9.7 \cdot 10^{19} \mathrm{~cm}^{-2}, \varphi=1.5 \cdot 10^{11} \mathrm{~cm}^{-2} \mathrm{~s}^{-1}$

IA annealed $\left(475{ }^{\circ} \mathrm{C} / 150 \mathrm{~h}\right)$ after irradiation

IAI-1 reirradiated, $\Phi=1.5 \cdot 10^{19} \mathrm{~cm}^{-2}, \varphi \lambda 1.2 \cdot 10^{11} \mathrm{~cm}^{-2} \mathrm{~s}^{-1}$ 
Table 6. Composition (at.-\%) reported in [10] of clusters observed by 3DAP in neutron irradiated VVER440-type weld and calculated $A$-ratio.

$\begin{array}{llllllll}\text { Location of cluster } & \mathrm{Cu} & \mathrm{Mn} & \mathrm{Si} & \mathrm{Ni} & \mathrm{P} & \mathrm{Fe} & \text { A-ratio }\end{array}$

$\begin{array}{llllllll}\text { Matrix } & 20.3 & 4.2 & 3.7 & 3.3 & 3.4 & \text { bal. } & 3.85\end{array}$

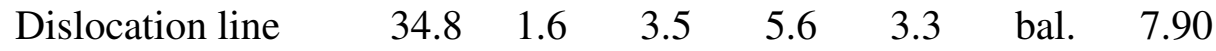


List of figures

Figure 1. Limiting cases for the reirradition behaviour of the brittle-to-ductile transition temperature as compared with the original irradiation, (a) horizontal shift, (b) vertical shift, (c) shift from the origin, (d) intermediate case.

Figure 2. Coherent neutron scattering cross section for unirradiated and irradiated conditions and after post-irradiation annealing; (a) total cross section, $\mathrm{d} \Sigma / \mathrm{d} \Omega_{\mathrm{tot}}$, (b) nuclear cross section, $\mathrm{d} \Sigma / \mathrm{d} \Omega_{\text {nuc }}$, (c) magnetic cross section, $\mathrm{d} \Sigma / \mathrm{d} \Omega_{\mathrm{mag}}$.

Figure 3. Volume distribution function, $c_{R}$, for unirradiated and irradiated conditions and after post-irradiation annealing calculated by Fourier transformation of curves from figure $2 \mathrm{c}$ assuming non-magnetic scatterers.

Figure 4. Coherent neutron scattering cross section for annealed and reirradiated conditions and after post-irradiation annealing; (a) total cross section $\mathrm{d} \Sigma / \mathrm{d} \Omega_{\text {tot }}$, (b) nuclear cross section $\mathrm{d} \Sigma / \mathrm{d} \Omega_{\text {nuc }}$, (c) magnetic cross section $\mathrm{d} \Sigma / \mathrm{d} \Omega_{\text {mag. }}$.

Figure 5. Volume distribution function, $c_{R}$, for annealed and reirradiated conditions and after post-irradiation annealing calculated by Fourier transformation of curves from figure $4 \mathrm{c}$ assuming non-magnetic scatterers. 

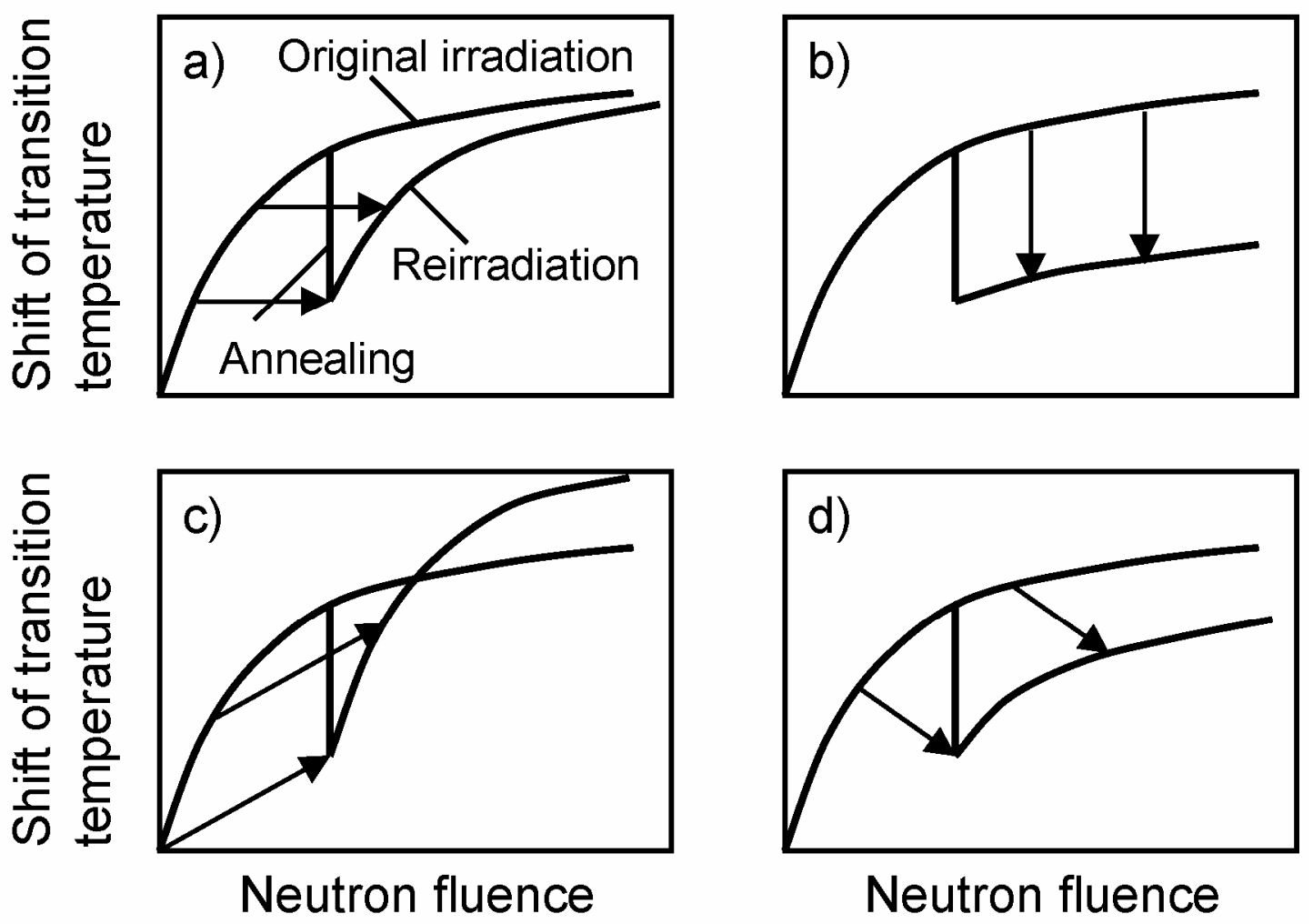

Figure 1 


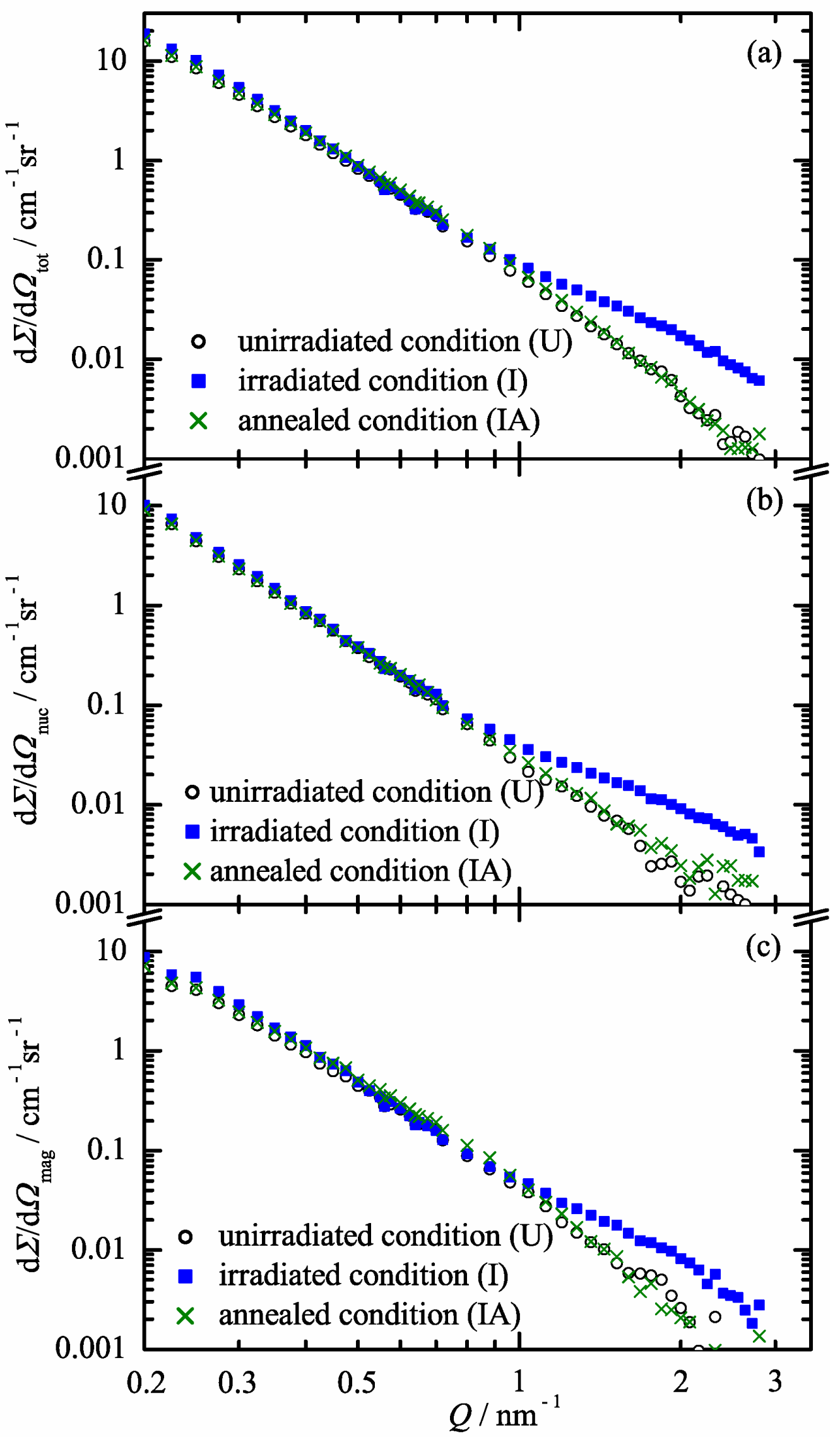

Figure 2 


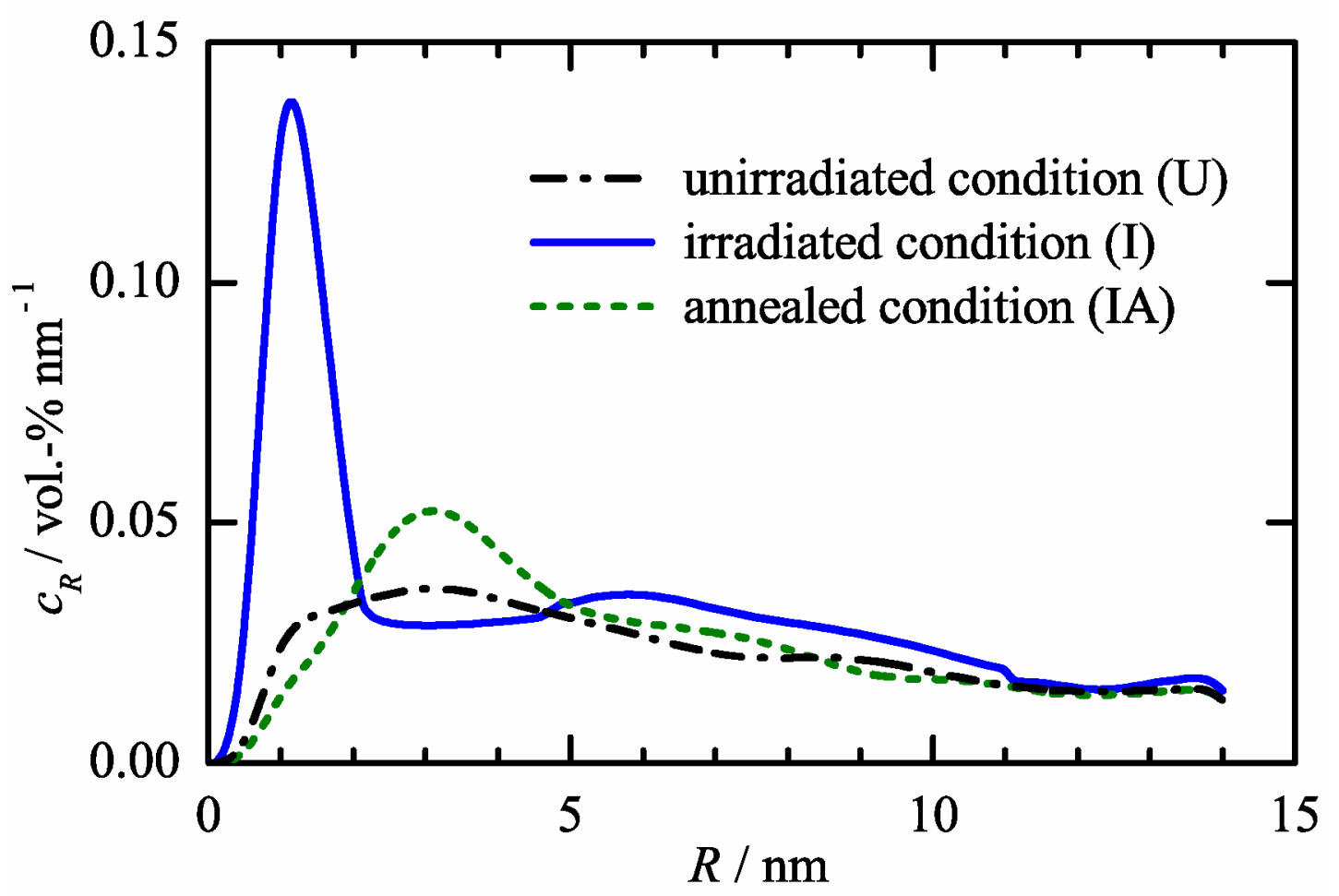

Figure 3 


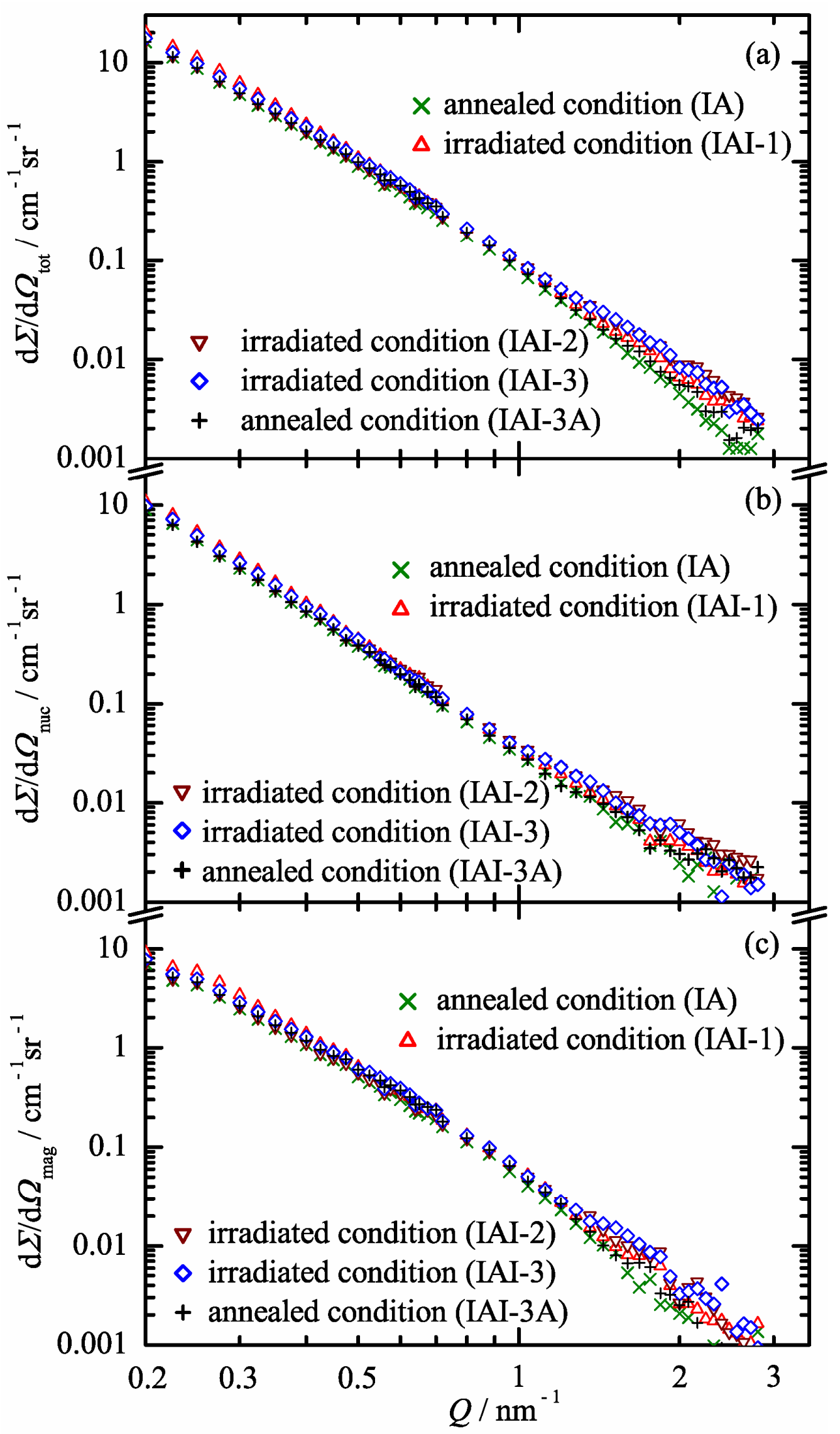

Figure 4 


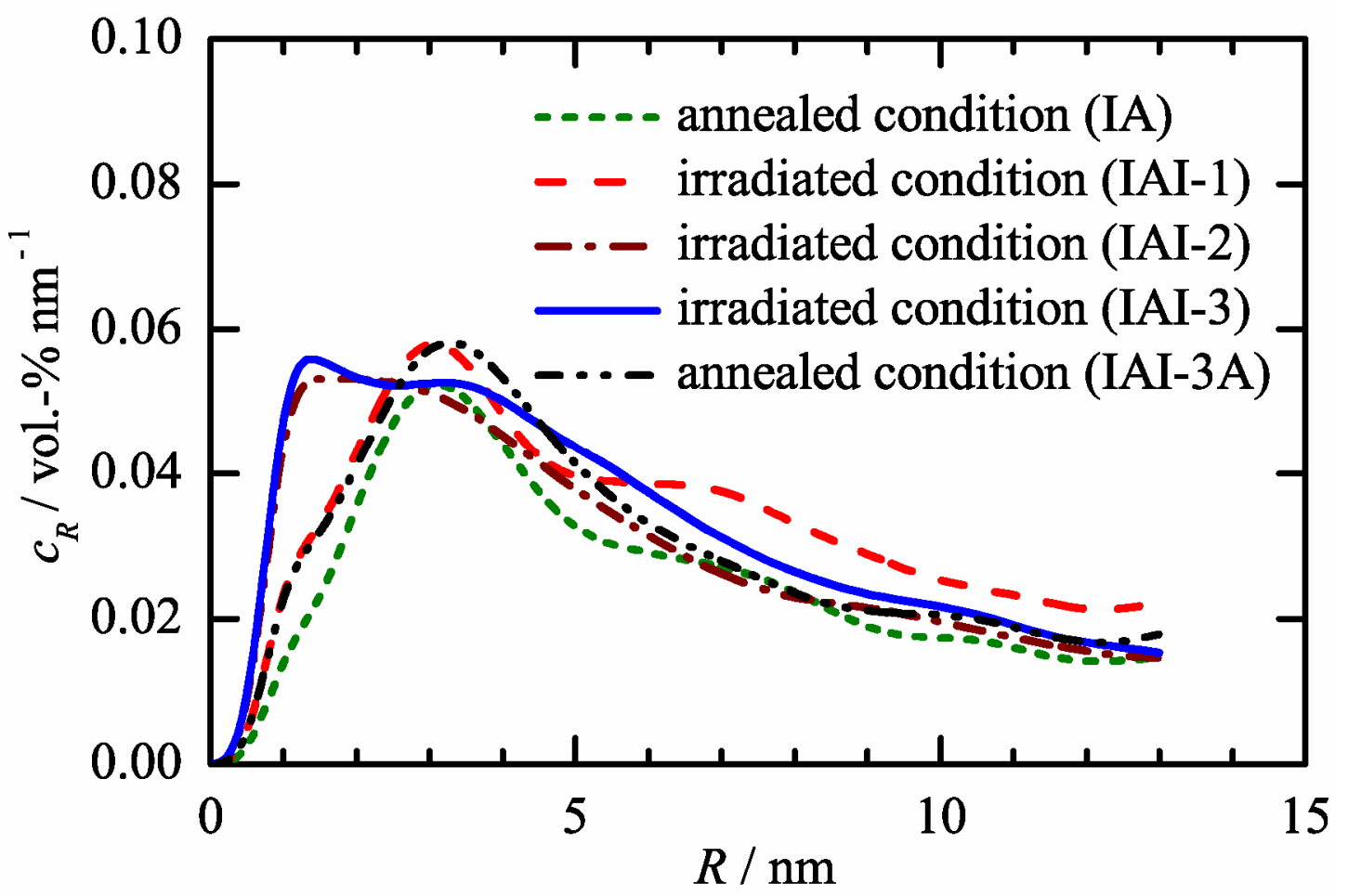

Figure 5 

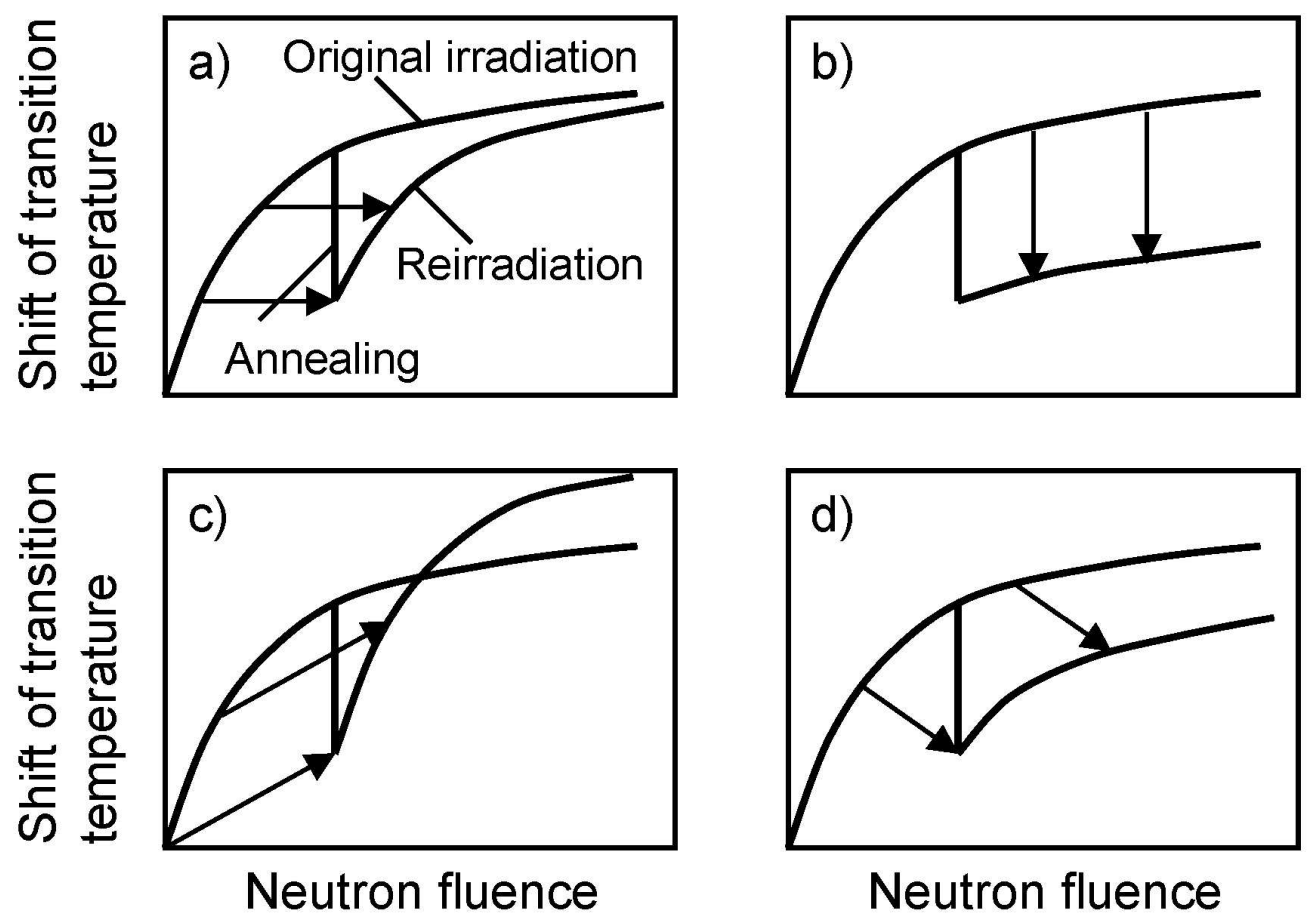

$146 \times 103 \mathrm{~mm}(300 \times 300$ DPI $)$ 


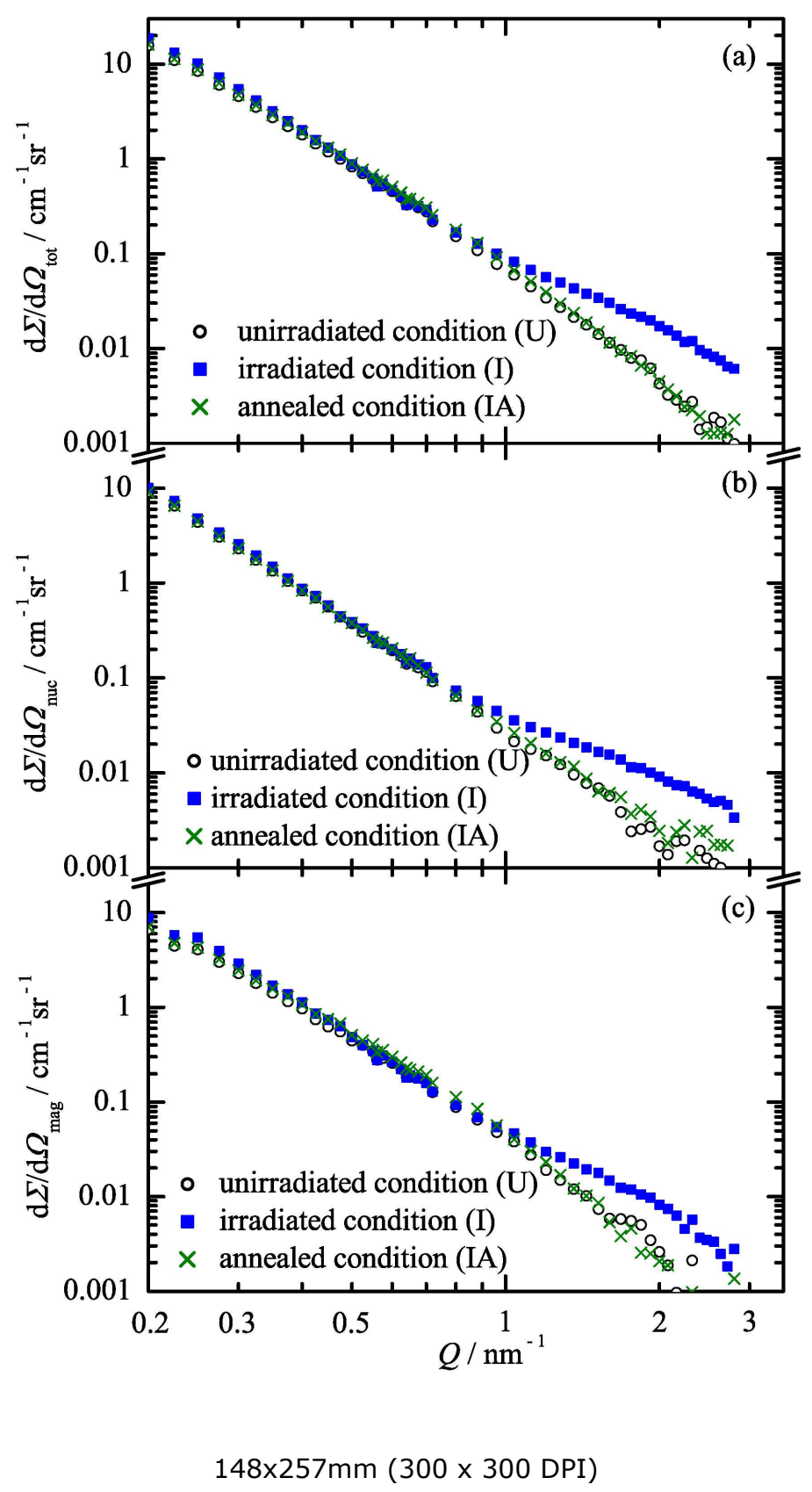




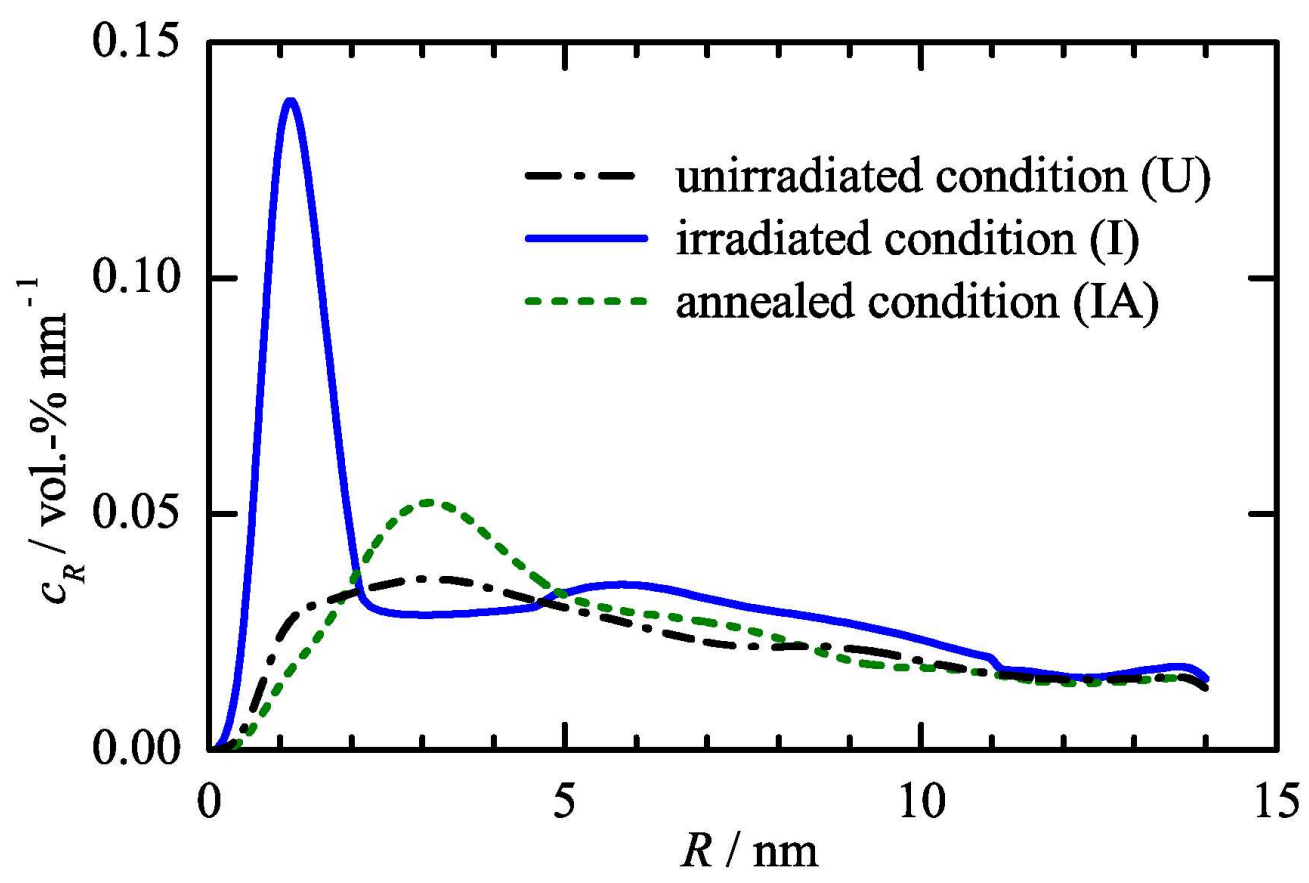

$145 \times 98 \mathrm{~mm}(300 \times 300$ DPI $)$ 


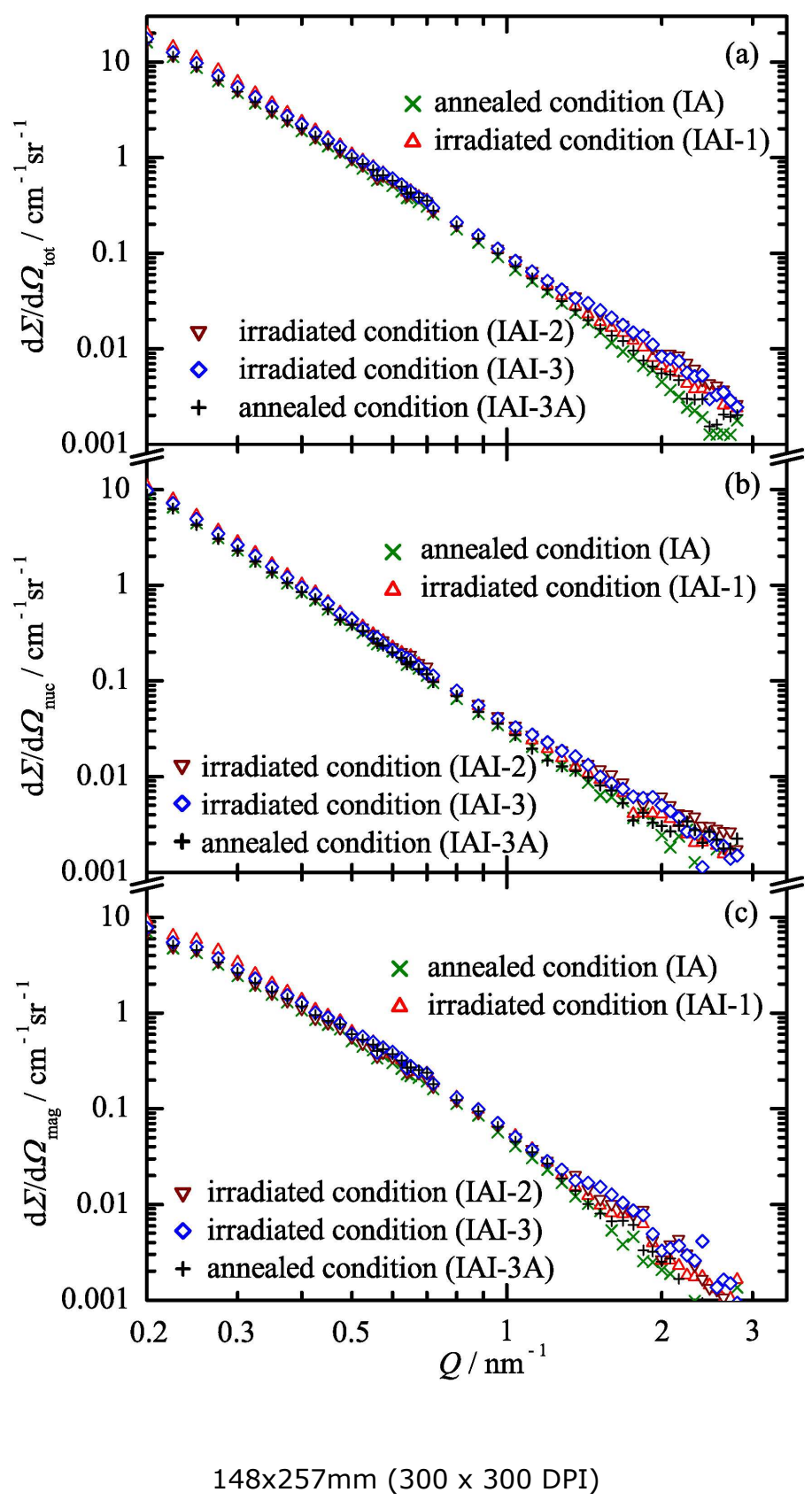

http://mc.manuscriptcentral.com/pm-pml 


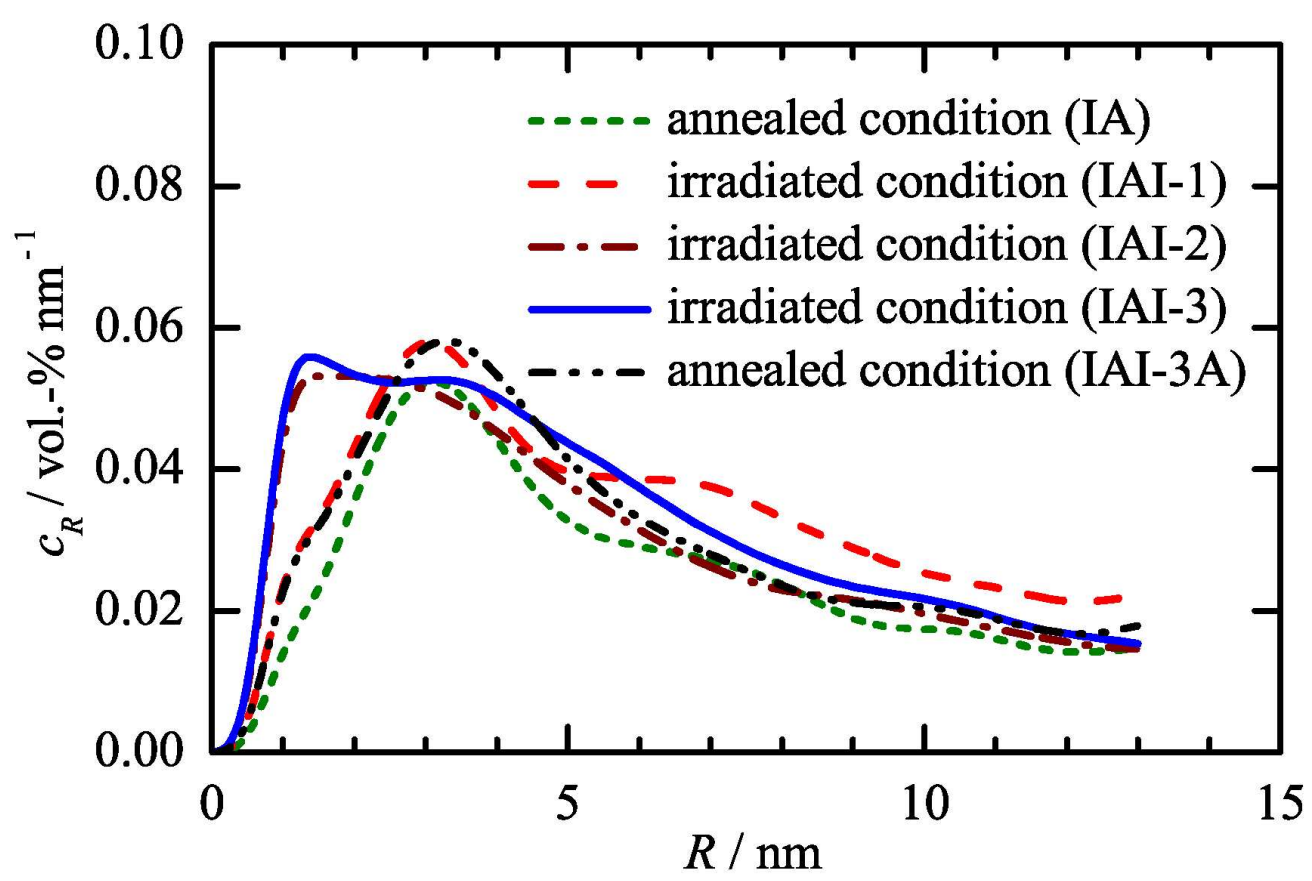

$145 \times 98 \mathrm{~mm}(300 \times 300$ DPI $)$ 


\title{
SANS response of VVER440-type weld material after neutron irradiation, post- irradiation annealing and reirradiation
}

\author{
A. ULBRICHT†, F. BERGNER*†, J. BÖHMERT $\dagger$, M. VALO $\ddagger$, M.-H. MATHON§, \\ A. HEINEMANNף
}

† Forschungszentrum Rossendorf, P.O.B 510119, 01314 Dresden, Germany

‡ VTT Industrial Systems, P.O.B. 17042, 02044 VTT, Finland

$\S$ Laboratoire Léon Brillouin, CEA Saclay, 91191 Gif-sur-Yvette Cedex , France

I Hahn-Meitner-Institut Berlin, Glienicker Str. 100, 14109 Berlin, Germany

It is well accepted that the reirradiation behaviour of reactor pressure vessel (RPV) steel after annealing can be different from the original irradiation behaviour. We present the first small-angle neutron scattering (SANS) study of neutron irradiated, annealed and reirradiated VVER440type RPV weld material. The SANS results are analysed both in terms of the size distribution of irradiation-induced defect/solute atom clusters and in terms of the ratio of total and nuclear scattering intensity in a saturation magnetic field (A-ratio). The measured A-ratio is compared with calculations performed on the basis of the cluster composition reported for a similar weld material investigated by means of three-dimensional atom probe field ion microscopy. The observed deviation between both estimates and possible reasons for the discrepancy are discussed. Special emphasis is placed on the differences between the materials response to the original irradiation and to reirradiation after annealing. The results indicate that reirradiation-induced clusters are slightly different in their average composition and their formation saturates at a lower volume fraction than in the case of the original irradiation.

Keywords: SANS; Steel; Neutron irradiation; Embrittlement; Annealing

\section{Introduction}

Thermal annealing of embrittled reactor pressure vessel (RPV) steel and weld material is a well-known option for life extension of light water reactors [1]. In fact, large-scale annealing of the core belt region for the purpose of life extension was successfully applied in a number of cases including the first-generation VVER440type RPVs [1]. In the last three decades major scientific efforts have been focussed on the estimation of the temperature-time regime for optimum recovery of mechanical properties [2,3], a methodology for verification of the annealing effect (i.e. degree of reversal of irradiation hardening and embrittlement) using non-destructive techniques $[2,3]$ or small-specimen tests [3,4], and the phenomenological description of the reirradiation behaviour of RPV steels based on mechanical testing [3,5-7].

The phenomenological description of the reirradiation behaviour has been essentially founded on the dependence of the most important property change, i.e. the shift of the brittle-to-ductile transition temperature, on neutron fluence. If partial

*Corresponding author. Email: F.Bergner@fz-rossendorf.de 
recovery of the transition temperature is assumed as a result of annealing, the following three limiting cases can be identified: (1) The horizontal shift approach, according to which the reirradiation curve is obtained by a horizontal shift of the original curve (see figure 1a). (2) The vertical shift approach, according to which the reirradiation curve is obtained by a vertical shift of the original curve (see figure 1b). (3) The conservative approach based on a shift from the origin (see figure 1c). Additionally, an intermediate case between horizontal and vertical shift is depicted in figure 1d. The four cases will result in different margins for life extension. It is therefore desirable to have an approach capable of predicting the true reirradiation behaviour on a sound microstructural basis.

[Insert figure 1 about here]

However, mechanistic understanding of the materials response to neutron irradiation, post-irradiation annealing and reirradiation is still far from being satisfactory or even complete. Indirect conclusions about the mechanisms underlying the annealing and reirradiation response of RPV steels and welds have been drawn via analysing results of mechanical testing [6-8] and fractographic observations [9] of these materials. More direct evidence has been collected by means of quantitative TEM [9] and three-dimensional atom probe field ion microscopy (3DAP) [10]. In particular, it was shown that reirradiation-induced microstructural changes are different from the original irradiation response not only quantitatively but also in nature [10].

In the present paper results of small-angle neutron scattering (SANS) experiments performed for a VVER440-type weld material including three reirradiated conditions and a reirradiated and annealed condition are reported. In some contrast with TEM and state-of-the-art 3DAP, SANS measurements allow a statistically representative size distribution of irradiation-induced defect/solute atom clusters averaged over a macroscopic volume of some ten $\mathrm{mm}^{3}$ to be obtained. Furthermore, SANS is capable of providing some reduced information in terms of the $A$-ratio (see below) related to cluster composition including fractions of vacancies or self-interstitial atoms (SIA). On the other hand, 3DAP provides direct element-specific information on composition not accessible by means of SANS. Investigations of neutron irradiated and annealed RPV steels based on a combination of SANS and 3DAP were reported in the literature [11,12]. In particular, the cluster composition deduced by 3DAP was checked against SANS data in [12]. The discussion in the present work is essentially based on contrasting SANS results with those obtained by Pareige et al. [10] using 3DAP for similar VVER440-type weld material.

\section{Experiments}

The material investigated is VVER440-type weld material Sv10KhMFT of the composition given in table 1 in a total of seven different irradiation conditions summarized in table 2. Irradiations were carried out at surveillance positions of NPP Loviisa (Finland). Irradiation temperature was $270^{\circ} \mathrm{C}$. Specimens were provided by VTT Espoo (Finland) as slices of dimensions of $10 \mathrm{~mm}$ by $10 \mathrm{~mm}$ and thickness of $0.8 \mathrm{~mm}$. No additional surface preparation was needed for the SANS experiments.

[Insert table 1 about here]

[Insert table 2 about here] 
The SANS measurements were carried out at the PAXE spectrometer of the Orphee research reactor at LLB Saclay [13] and at the BENSC V4 spectrometer of HMI Berlin [14]. A neutron wavelength of $0.5 \mathrm{~nm}( \pm 10 \%)$ at half maximum was used. A beam diameter of $8 \mathrm{~mm}$ was realized by a Cd aperture fixed directly in front of the sample. The SANS intensity was measured with a 2-dimensional $64 \mathrm{~cm} \times 64$ $\mathrm{cm} \mathrm{BF}_{3}$-detector (LLB) or ${ }^{3} \mathrm{He}$-detector (HMI) at two different sample-detector distances of about $1 \mathrm{~m}$ and $4 \mathrm{~m}$ corresponding to a measuring range of the scattering vector of approximately $0.13 \mathrm{~nm}^{-1}$ to $2.9 \mathrm{~nm}^{-1}$. During the SANS measurements the samples were placed in a saturation magnetic field of $1.4 \mathrm{~T}$ perpendicular to the neutron beam direction. The scattering intensity was calibrated by direct determination of the intensity of the incident beam and the calibration was checked comparing the measuring results for a reference sample of known scattering cross section.

SANS data were processed by software routines of LLB and BENSC. In particular, the angular dependence of the scattered neutron intensity was utilized to separate the magnetic contribution from the total scattered intensity.

\section{Results}

The measured scattering cross section is composed of a coherent and an incoherent contribution. The incoherent contribution was eliminated assuming the scattering intensity to follow Porod's law (i.e. to be proportional to $Q^{-4}$ ) for large $Q$ values. After subtraction of the incoherent contribution the coherent scattering cross section is determined as shown in figure 2 for the unirradiated (U), the irradiated (I), and the irradiated and annealed (IA) conditions of the VVER440-type weld material. Irradiation clearly raises the nuclear and the magnetic contribution to the scattering cross section for $Q>0.8 \mathrm{~nm}^{-1}$ (see figure $2 \mathrm{~b}, \mathrm{c}$ ) in an analogous manner. Annealing reduces the effect to the initial level and gives rise to a small increase of the magnetic contribution in the $Q$ range from 0.5 to $0.8 \mathrm{~nm}^{-1}$ (see figure 2c).

[Insert figure 2 about here]

Further analysis is based on the indirect transformation method [15] and provides the volume distribution or the number density distribution of scatterers without assuming a certain type of distribution. According to our standard analysis we have assumed that the system consists of isolated scattering particles in a homogeneous matrix (two-phase approach), the particles are spherical and non-magnetic and the particle size is spatially uncorrelated. Multiple scattering is minimized by choosing a sufficiently small sample thickness on the expense of scattering intensity and measuring time.

The assumption of non-magnetic scatterers may be invalid in the case of significant fractions of $\mathrm{Fe}$ or $\mathrm{Ni}$ in clusters. The size distributions given in this paper were still valid on a relative scale in this case, but the absolute values of the volume fractions and number densities of scatterers would be incorrect. The issue is discussed in [12] but not solved completely. However, if the cluster composition is given, the size distribution of clusters can be calculated from the nuclear scattering cross section without any assumption on the magnetic character of the clustered atoms. 
The volume distribution of clusters obtained under the assumption of nonmagnetic scatterers is presented in figure 3. It exhibits the appearance typical of RPV steels: a broad distribution without a clear maximum in the size range up to $10 \mathrm{~nm}$ in the unirradiated condition and an additional sharp peak near a radius of $1 \mathrm{~nm}$ in the irradiated condition. Annealing reduces the volume fraction corresponding to the peak position to the initial level. Simultaneously, a new smaller peak centred at about $3 \mathrm{~nm}$ of radius appears. These effects can be traced back to the scattering curves (see figure 2c).

\section{[Insert figure 3 about here]}

The same procedure applied to the reirradiated samples yields the results depicted in figures 4 and 5 . We have observed that: (1) There is a reirradiation-induced increase of the volume fraction of scatterers in the size range around $1 \mathrm{~nm}$ of radius as for the original irradiation. (2) The increase due to reirradiation is smaller than due to the original irradiation. (3) The increase saturates at a neutron fluence corresponding to condition IAI-2. (4) The volume fraction of scatterers formed in the size range around $3 \mathrm{~nm}$ as a result of annealing remains unchanged. (5) Annealing of the reirradiated material in turn results in a reduction of the volume fraction around $1 \mathrm{~nm}$ of radius and a slight increase of the volume fraction of scatterers in the size range around $3 \mathrm{~nm}$.

[Insert figure 4 about here] [Insert figure 5 about here]

The above observations suggest the distinction of two particle size ranges: The first one from $0.5 \mathrm{~nm}$ (lower detection limit of SANS for commercial Fe-based alloys) to about $2.5 \mathrm{~nm}$ essentially applies to the irradiation or reirradiation response. The second range from about $2.5 \mathrm{~nm}$ to $4.5 \mathrm{~nm}$ is important for the annealing response after irradiation or reirradiation. The total volume fractions, $c$, of scatterers related to these size ranges and measured values of Vickers hardness, HV10, are listed in table 3 for each of the conditions investigated.

[Insert table 3 about here]

The A-ratio is defined as ratio of the SANS cross sections perpendicular and parallel to the direction of the applied saturation magnetic field and can be expressed as the ratio of the total SANS cross section and the nuclear cross section. The A-ratio can also be calculated after Fourier transformation, i.e. in the size space. As in the case of the volume fraction of irradiation-induced clusters, the A-ratio was estimated by integrating the respective size distributions over either size range $(0.5$ to $2.5 \mathrm{~nm}$ and 2.5 to $4.5 \mathrm{~nm}$ ) separately. The estimated values of the $A$-ratio are compiled in table 4 along with the irradiation-induced increase of the volume fraction of scatterers and the irradiation-induced hardness increase. In table 4 the unirradiated condition, $U$, is taken as reference for conditions I and IA, whereas the irradiated and annealed condition, IA, is taken as reference for conditions IAI-1, IAI-2, IAI-3 and IAI-3A. Of course, the $A$-ratio can only be calculated provided that a significant volume fraction of scatterers has formed.

[Insert table 4 about here] 


\section{Discussion}

\subsection{Original irradiation response}

4.1.1. Magnetic scattering. Analysis of the measured SANS data is limited by the fact that the detailed composition of the detected irradiation-induced clusters is generally unknown. On the other hand, one has the freedom to start either from the nuclear scattering cross section or from the magnetic cross section. Of the needed assumptions about the nuclear or magnetic scattering length of the clusters, the one about the magnetic scattering length is less restricting under the present conditions. Indeed, the assumption of non-magnetic scatterers is absolutely valid in the case of pure $\mathrm{Cu}$ clusters or pure vacancy clusters and the magnetic contrast is maximum. If the clusters contain Fe atoms, the magnetic contrast may be reduced with the amount of reduction depending on the magnetic moment of the Fe atoms in the cluster. If we assume the addition of 50 at.- $\%$ Fe of the same magnetic scattering length as matrix $\mathrm{Fe}$, the magnetic contrast will be reduced by a factor of 4 . Therefore, the true volume fractions may be up to about four times (but not orders of magnitude) larger than those specified in figures 3 and 5 and tables 3 and 4 .

The above estimation shows that the major observations of the present investigation, namely the formation of irradiation-induced clusters in the size range from 0.5 to $2.5 \mathrm{~nm}$ (radius), the disappearance of these clusters after annealing accompanied by the appearance of scatterers in the size range from 2.5 to $4.5 \mathrm{~nm}$, and the appearance of reirradiation-induced clusters in the former size range, hold true. The calculated volume fractions are minimum values.

4.1.2. A-ratio. A more detailed discussion of the present results depends on the knowledge about the composition of the scatterers. However, the composition of the detected irradiation-induced clusters cannot be inferred from SANS measurements alone. On the other hand, any candidate composition can be checked for consistency by comparing calculated and measured values of the A-ratio [12]. Cluster compositions observed by means of 3DAP are reported in [10] for similar VVER440type weld material $(0.16$ wt.-\% $\mathrm{Cu})$ irradiated under similar conditions summarized in table 5. These clusters are characterized as coherent $\mathrm{Cu}-\mathrm{Si}-\mathrm{Mn}-\mathrm{Ni}$-P-enriched clusters of about $2 \mathrm{~nm}$ in diameter and of a number density of $5 \times 10^{23} \mathrm{~m}^{-3}[10]$.

[Insert table 5 about here]

In order to check for consistency of the typical compositions reported in [10] with the A-ratios obtained in the present case, a theoretical A-ratio was calculated according to equations (1)-(3).

$$
A=1+\left(\frac{\sum_{i} n_{i}^{\text {Cluster }} b_{\text {mag }, i}^{\text {Cluster }}-\sum_{i} n_{i}^{\text {Matrix }} b_{\text {mag }, i}^{\text {Matrix }}}{\sum_{i} n_{i}^{\text {Cluster }} b_{\text {nuc }, i}^{\text {Cluster }}-\sum_{i} n_{i}^{\text {Matrix }} b_{\text {nuc }, i}^{\text {Matrix }}}\right)^{2}
$$

In equation (1), $b$ and $n$ refer to scattering length and atomic fraction, respectively, subscripts nuc and mag refer to nuclear and magnetic scattering length, respectively, 
and summation is performed over all types of atoms constituting cluster or matrix. If we restrict ourselves to the species the clusters are enriched with [10], ignore strain fields, assume the matrix to be pure Fe and assume the magnetic moments of Fe and $\mathrm{Ni}$ in the clusters to be the same as in the matrix, equation (1) is simplified to

$$
A=1+\left(\frac{6.0\left(n_{F e}-1\right)+1.0 n_{N i}}{9.45\left(n_{F e}-1\right)+10.3 n_{N i}+7.72 n_{C u}-3.75 n_{M n}+4.15 n_{S i}+5.13 n_{P}}\right)^{2}
$$

where the coefficients in the nominator are the values in units of $\mathrm{fm}\left(10^{-15} \mathrm{~m}\right)$ of the magnetic scattering length for Fe and $\mathrm{Ni}$ [16], the coefficients in the denominator are the values in units of $\mathrm{fm}$ of the nuclear scattering length for $\mathrm{Fe}, \mathrm{Ni}, \mathrm{Cu}, \mathrm{Mn}, \mathrm{Si}$, and $\mathrm{P}$ [17], and where

$$
n_{\mathrm{Fe}}+n_{N i}+n_{\mathrm{Cu}}+n_{\mathrm{Mn}}+n_{\mathrm{Si}}+n_{P}=1
$$

in the case of vacancy-free clusters. In the case of clusters containing a vacancy fraction, $n_{\mathrm{vac}}$, the concentrations in equation (3) have to be rescaled according to equation (4):

$$
n_{\mathrm{Fe}}+n_{\mathrm{Ni}}+n_{\mathrm{Cu}}+n_{\mathrm{Mn}}+n_{\mathrm{Si}}+n_{\mathrm{P}}=1-n_{\mathrm{vac}}
$$

The cluster compositions reported in [10] and the A-ratios calculated assuming vacancy-free clusters of the reported composition are summarized in table 6 .

[Insert table 6 about here]

We find the measured $A$-ratio of the irradiation-induced clusters $(1.6 \pm 0.1)$ to be significantly smaller than the calculated ones (3.85 and 7.90). The deviation in case of the composition reported for clusters located at dislocations (7.90) is larger than for clusters located in the matrix (3.85). It may be noticed that the discrepancy would even be more significant in both cases, if the magnetic scattering length per $\mathrm{Fe}$ or $\mathrm{Ni}$ atom for the cluster were smaller than for the matrix. There are several possible reasons for the observed discrepancy:

(1) Clusters characterized in [10] may contain a significant fraction of vacancies not detected by means of 3DAP. Assuming a vacancy fraction, $n_{\mathrm{vac}}=0.46$, in the clusters while keeping all other elements in the reported proportion will reduce the $A$ ratio from 3.85 (for the case of cluster located in the matrix, see table 6) to the observed level of 1.6. Evidence for the contribution of vacancies to Cu-vacancy clusters is reported in [18] for Fe-Cu model alloys. The presence of small clusters containing 4 to 6 vacancies in neutron irradiated VVER440-type weld material was concluded from positron lifetime measurements [19].

(2) Mn would have an even stronger effect than vacancies because of its negative nuclear scattering length, but there is certainly no doubt about the level of $\mathrm{Mn}$ reported in [10]. However, taking the reported upper limit instead of the mean value will reduce the A-ratio from 3.85 to 3.36 . Properly varying the levels of the other elements within the error range gives rise to an additional maximum reduction of the A-ratio up to about 3 but not to the observed level of 1.6.

(3) There may exist a second population of irradiation-induced features of different nature. Nanovoids and self-interstitial atom (SIA) clusters, which are not 
detectable by 3DAP in complex commercial alloys [10], are candidates. In fact, both pure nanovoids and pure SIA clusters would give an A-ratio of 1.4 (equations (2) and (4)) thus allowing for an average $A$-ratio of 1.6. Evidence for the contribution of SIA clusters (loops) is reported in [9] for VVER440-type weld material.

(4) Strain fields are reported to decrease the A-ratio in the case of Fe-Cu clusters [13]. Coherency strain induced by atom size misfit is supposed to be too small to explain the observed deviations in the present case, especially if the clusters contain vacancies, which are expected to compensate for the atom size misfit at least partly.

4.1.3. Nuclear scattering. Our standard analysis is based on the magnetic scattering cross section, because in most cases the cluster composition is not known in advance. However, if the cluster composition is given, the size distribution of scatterers (and related quantities) can be calculated from the nuclear scattering cross section without any assumption about the magnetic character of the scatterers. For the present weld material in the irradiated condition, the estimated total volume fraction of irradiationinduced scatterers in the size range from 0.5 to $2.5 \mathrm{~nm}$ is $4 \mathrm{vol} .-\%$, if the estimation is based on the reference composition for clusters in the matrix (see table 6). It is 5 vol.-\%, if the calculation is based on the composition for clusters at dislocations (see table 6). These values are 40 to 50 times larger than the estimate obtained from the magnetic cross section assuming non-magnetic scatterers (see table 4). With reported $\mathrm{Cu}$ fractions in the clusters between 20 and 35 at.-\% (see table 6), a minimum $\mathrm{Cu}$ content of the weld material of 0.80 at.-\% or 0.91 wt.-\% would be necessary to obtain a volume fraction as high as 4 vol.-\% of coherent clusters. Clearly, this is contrary to the actual $\mathrm{Cu}$ content of 0.14 wt.-\% (see table 1 ).

This discrepancy cannot be fully resolved by taking into account measuring errors and marginal differences in the materials or irradiation conditions. The possible reasons of the deviation are similar as discussed above. In particular, a vacancy fraction, $n_{\mathrm{vac}}=0.46$, in the clusters along with the other solute atoms in the reported proportion (see table 6, matrix) would give a calculated $A$-ratio of 1.6 (equations (2) and (4)), which is in agreement with the measured A-ratio, and simultaneously a volume fraction of clusters of 0.24 vol.- $\%$, which is also reasonable in the following respects:

(1) The value of 0.24 vol.-\% does not conflict with the total $\mathrm{Cu}$ content of the weld material of $0.14 \mathrm{wt} .-\%$ or 0.12 at.-\%. In fact, even the maximum estimate of the $\mathrm{Cu}$ fraction in clusters $\left(1-n_{\mathrm{vac}}\right) \times 35$ at.- $\%=19$ at.-\% requires only about 0.05 at.- $\%$ $\mathrm{Cu}$. The balance of at least 0.07 at.-\% consists of matrix $\mathrm{Cu},(0.05 \pm 0.02)$ at.- $\%$ according to [10], and $\mathrm{Cu}$ in clusters of radius smaller than $0.5 \mathrm{~nm}$, i.e. below the detection limit of SANS.

(2) The value of 0.24 vol.-\% compares well with the cluster fraction of 0.25 vol.-\% calculated from the reported estimate of the number density of clusters, $N=5 \times 10^{23} \mathrm{~m}^{-3}$, in the similar weld material [10].

(3) Finally, the value of 0.24 vol.- $\%$ is also consistent with the fraction of 0.17 vol.- $\%$ one would calculate from the magnetic scattering cross section assuming the same cluster composition as above (46\% vacancies plus solute atoms in the proportion according to table 6) and the same magnetic scattering length of the Fe atoms in the cluster as in the matrix.

Therefore, it seems to be reasonable to assume an average vacancy fraction, $n_{\mathrm{vac}}=0.46$, and an average total fraction of atoms, $n_{\mathrm{tot}}=0.54$, in the clusters, the latter partitioned in the proportion according to table 6. However, SANS is a volumeintegrating method and it cannot be decided, whether all clusters have about the same 
composition, or there is a broad spectrum of compositions, or there are two types of clusters of essentially different composition. In particular, it is possible that the estimated vacancy fraction forms nanovoids not detectable by 3DAP and the remaining atom fraction forms clusters of the composition deduced from the 3DAP measurements. The monomodal distribution of irradiation-induced clusters observed in the present work, the monomodal distributions observed after stepwise annealings of other RPV steels [20], and the observed Arrhenius-like annealing behaviour [20] seem to be in contrast with the latter variant.

In the case of a unique type of defect/solute clusters, defects of the SIA type are energetically unfavourable because of large elastic strains resulting in combination with oversize $\mathrm{Cu}$ atoms. In the case of two distinct types of defects, it is possible that the second population is SIA clusters instead of nanovoids discussed above. However, planar SIA clusters (loops) are characterized by a much weaker contrast [21] than spherical nanovoids and a much larger number density of SIA clusters, $N \gtrsim 10^{25} \mathrm{~m}^{-3}$, would therefore be necessary to account for the observed SANS cross sections. This estimate strongly conflicts with the values of about $2 \times 10^{21} \mathrm{~m}^{-3}$ and $5 \times 10^{21} \mathrm{~m}^{-3}$ reported in [19] and [9], respectively, on the basis of TEM observations of similar VVER440-type weld material irradiated to even higher neutron fluences. The relevant conclusion is that SIA loops are not ruled out by the present SANS experiments, but they do not contribute significantly to the irradiation-induced increase of the SANS cross section. The situation essentially changes, if SIA clusters are decorated (e.g. with undersize Mn atoms), but this type of clusters was not reported in [10].

4.1.4. Hardness. The observed significant hardness increase (see table 4) is related to the formation of irradiation-induced clusters via the interaction of these clusters with dislocations. The hardness increase confirms the physical significance of the conclusions drawn about the formation of irradiation-induced clusters.

\subsection{Annealing response}

Annealing is accompanied by the disappearance of the irradiation-induced volume fraction of clusters in the size range from 0.5 to $2.5 \mathrm{~nm}$ and the formation of a smaller fraction in the size range from 2.5 to $4.5 \mathrm{~nm}$. The high $A$-ratio $(A \gtrsim 10)$ indicates that the scatterers observed after annealing are Cu-rich precipitates. This is in agreement with the conclusion inferred by Pareige et al. [10] from the reported 3DAP observations after reirradiation [10]. The Cu-rich precipitates are still coherent with the Fe matrix.

It is interesting to note that, in contrast with the above observation for weld material (0.14 wt.-\% Cu), significant annealing-induced cluster growth (or coarsening) is not observed in RPV base material with $\mathrm{Cu}$ contents less than 0.2 wt.$\%$ at an annealing temperature of $475^{\circ} \mathrm{C}[20,22,23]$. A possible explanation for this difference is the lower carbon content in the weld.

The assumption of non-magnetic scatterers is justified in the case of $\mathrm{Cu}$-rich precipitates. Therefore, the volume fraction of $0.026 \%$ (see table 4 ) obtained from the magnetic scattering cross section is valid. This value is smaller by a factor of 4 to 10 than the volume fraction of $0.1 \%$ to $0.24 \%$ (depending on the underlying assumptions, see above) of irradiation-induced clusters in the size range from 0.5 to $2.5 \mathrm{~nm}$ before annealing. A similar behaviour was observed before by means of 3DAP for a French 
CHOOZ RPV steel [24]. It is interesting to notice that the estimated volume fractions before and after annealing roughly correspond to the same amount of $\mathrm{Cu}$.

The irradiation-induced hardness increase is almost completely reversed by annealing (see table 4). This is in agreement with both the dissolution of a substantial fraction of irradiation-induced clusters in the size range from 0.5 to $2.5 \mathrm{~nm}$ responsible for the original hardness increase and a lower hardening capacity of the smaller fraction of $\mathrm{Cu}$ precipitates in the size range from 2.5 to $4.5 \mathrm{~nm}$ formed during annealing.

\subsection{Reirradiation response}

The basic observation from the SANS experiments for the reirradiated specimens (conditions IAI-1, IAI-2 and IAI-3) is that clusters are formed in the same size range and with a similar distribution as in the case of the original irradiation (condition I). These clusters are characterized by a slightly higher $A$-ratio than for the original irradiation and the $A$-ratio further increases with increasing neutron fluence (see table 4). Furthermore, as the agreement of the volume fractions for conditions IAI-2 and IAI-3 shows, the formation of reirradiation-induced clusters observed by SANS strongly decelerates or even saturates in the fluence range near or below the fluence corresponding to condition IAI-2. Provided the magnetic character of the reirradiation-induced clusters and the clusters formed during the original irradiation is about the same the maximum value of the volume fraction is only half as high as the volume fraction observed after the original irradiation. No significant reirradiationinduced changes in the size range larger than $2.5 \mathrm{~nm}$ are observed.

To start with the common features (coinciding size ranges, similar A-ratios) it can be assumed that the reirradiation-induced clusters are not completely different in composition from the clusters present after the original irradiation. The observation reported in [10], namely that no $\mathrm{Cu}-\mathrm{Si}-\mathrm{Mn}-\mathrm{Ni}-\mathrm{P}-$-enriched clusters could be detected for the reirradiated condition, may be partly attributed to the relatively low neutron fluence (see table 5).

In order to discuss the differences, we have to ask, in which details does the starting point for the reirradiation differ from the starting point for the original irradiation. Two such details have been identified: (1) There are coherent Cu-rich precipitates in the size range from 2.5 to $4.5 \mathrm{~nm}$, which were not present at the beginning of the original irradiation. (2) As a consequence, the concentration of matrix $\mathrm{Cu}$ must be lower than prior to the original irradiation. Taking into account the total $\mathrm{Cu}$ content of the material $(0.12$ at.-\%) and the volume fraction of $\mathrm{Cu}$-rich precipitates after annealing (0.026 vol.-\%) the matrix concentration of $\mathrm{Cu}$ is estimated to be lower than about 0.1 at.-\%. In addition, after annealing there may be remnants of the dissolved clusters at sizes well below the detection limit of SANS of about $0.5 \mathrm{~nm}$ (radius), which were also not present after the original irradiation.

On the one hand, the reduced concentration of matrix $\mathrm{Cu}$ after annealing is consistent with the fact that the maximum volume fraction of reirradiation-induced clusters is significantly less than after the original irradiation. On the other hand, the reduced matrix $\mathrm{Cu}$ concentration does not explain the increased A-ratio. On the contrary, the expected decrease of the $\mathrm{Cu}$ fraction in the clusters would reduce, not raise, the $A$-ratio.

The resolution of the latter discrepancy must be left for future work. However, any reduction of the average vacancy fraction in the reirradiation-induced clusters 
relative to the original irradiation would explain an increase of the A-ratio. A reduced vacancy fraction can be the result of a decrease of the steady-state matrix concentration of vacancies due to the operation of additional sinks, such as the observed Cu-rich precipitates in the size range from 2.5 to $4.5 \mathrm{~nm}$. In fact, there is evidence that coherent precipitates of oversize $\mathrm{Cu}$ atoms in Fe attract vacancies [25].

A consistent estimation of the partition of 0.12 at.-\% Cu onto defects of different size is summarized below for the reirradiated condition IAI-3: (1) About 0.026 at.-\% $\mathrm{Cu}$ is bound in Cu-rich precipitates in the size range from 2.5 to $4.5 \mathrm{~nm}$. (2) The $\mathrm{Cu}$ fraction contributing to clusters in the size range from 0.5 to $2.5 \mathrm{~nm}$ is half that for condition I, i.e. 0.025 at.-\%, if the compositions are assumed to be equal, or slightly higher, if a smaller vacancy fraction is assumed than for condition I. (3) Matrix $\mathrm{Cu}$ amounts to about 0.05 at.-\% according to [10]. (4) The balance $\mathrm{Cu}$ is bound in clusters smaller than $0.5 \mathrm{~nm}$ in radius.

Regarding hardness, the basic observation is a reirradiation-induced increase to about the same level as that observed after the original irradiation. What would be expected is an increase proportional to the square root of cluster volume fraction, in particular:

$$
H_{i}=H_{u}+a \sqrt{\Delta c}
$$

for linear superposition or

$$
H_{i}=\sqrt{H_{u}^{2}+b^{2} \Delta c}
$$

for quadratic superposition. In equations (5)-(6), $H_{\mathrm{i}}$ and $H_{\mathrm{u}}$ are the Vickers hardness values for the irradiated and unirradiated condition, respectively, and $\Delta c$ is the total volume fraction of irradiation- (or reirradiation-) induced clusters. $a$ and $b$ are coefficients related to obstacle strength and accounting for the units. If $H_{\mathrm{i}}$ and $H_{\mathrm{u}}$ are measured in common units (see table 3 ) and $\Delta c$ is expressed as a fractional quantity (instead of vol.-\% as in table 4), the values, $a=970$ and $b=3700$, are obtained for the original irradiation. Applying the same values to the reirradiation behaviour (condition IAI-3), estimates of the hardness value, $H_{\mathrm{i}}=233$ and $H_{\mathrm{i}}=227$, are obtained for linear and quadratic superposition, respectively. These values have to be compared with the hardness value measured for condition IAI-3, $H_{\mathrm{i}}=241$. The higher value of the measured hardness indicates a higher obstacle strength of reirradiationinduced clusters as compared with the original irradiation. The conclusion of different obstacle strengths is consistent with differing values of the $A$-ratio for the original irradiation and reirradiation.

As in the case of the first annealing (condition IA) the reirradiation-induced hardness increase is essentially reversed by annealing (see table 4). However, the reversal seems to be incomplete.

\section{Conclusions}

Irradiation-induced clusters in VVER440-type weld material are observed by SANS and contrasted with previous 3DAP measurements for similar weld material [10]. There is a discrepancy between the $A$-ratios measured by SANS and calculated on the 
basis of the reported composition. The conflict can be removed, if the average cluster is assumed to contain vacancies not detected by 3DAP.

Thermal annealing at $475^{\circ} \mathrm{C} / 100 \mathrm{~h}$ results in complete disappearance of irradiation-induced clusters in the size range from 0.5 to $2.5 \mathrm{~nm}$ accompanied by a reversal of the irradiation-induced hardness increase and in the formation of scatterers of radii between 2.5 and $4.5 \mathrm{~nm}$. Because of their high $A$-ratio $(A \gtrsim 10)$ these scatterers are identified as $\mathrm{Cu}$-rich precipitates.

As a result of reirradiation after annealing, clusters are formed in the same size range $(0.5-2.5 \mathrm{~nm})$ as for the original irradiation but their formation strongly decelerates or saturates at a smaller volume fraction. The new average cluster differs in composition from the original one.

The observed hardness change due to reirradiation indicates that the obstacle strength of the reirradiation-induced clusters is higher than that for the original irradiation.

Thermal annealing after reirradiation results in partial disappearance of irradiation-induced clusters in the size range from 0.5 to $2.5 \mathrm{~nm}$ and partial reversal of the irradiation-induced hardness increase.

\section{References}

[1] T. Planman, R. Pelli, K. Törrönen, Irradiation embrittlement mitigation, AMES Report No. 1, EUR 16072 EN, (European Commission, 1995).

[2] K. Popp, G. Brauer, W.-D. Leonhardt, et al., in Radiation Embrittlement of Nuclear Reactor Pressure Vessel Steels: An International Review, ASTM STP 1011, edited by L.E. Steele, (American Society for Testing and Materials, Philadelphia, 1989), pp. 188-205.

[3] R. Pelli, K. Törrönen, State of the art review on thermal annealing, AMES Report No. 2, EUR 16278 EN, (European Commission, 1995).

[4] A. Kryukov, P. Platonov, Ya. Shtrombakh, et al., Nucl. Engng. Design 16059 (1996).

[5] A.D. Amayev, A.M. Kryukov, M.A. Sokolov, in: Radiation Embrittlement of Nuclear Reactor Pressure Vessel Steels: An International Review, ASTM STP 1170, edited by L.E. Steele, (American Society for Testing and Materials, Philadelphia, 1993), pp. 369-379.

[6] J. Kohopää, R. Ahlstrand, Int. J. of Pressure Vessels and Piping 77575 (2000).

[7] Ya.I. Shtrombakh, Int. J. of Pressure Vessels and Piping 77585 (2000).

[8] R. Chaouadi, R. Gerard, J. Nucl. Mater. 34565 (2005).

[9] B.A. Gurovich, E.A. Kuleshova, O.V. Lavrenchuk, et al., J. Nucl. Mater. 264 333 (1999).

[10] P. Pareige, B. Radiguet, R. Krummeich-Brangier, et al., Phil. Mag. 85429 (2005).

[11] P. Pareige, P. Auger, S. Welzel, et al., in: Effects of Radiation on Materials: 19th Int. Symp., ASTM STP 1366, edited by M.L. Hamilton, A.S. Kumar, S.T. Rosinski, M.L. Grossbeck, (American Society for Testing and Materials, West Conhohocken, 2000), pp. 435-447.

[12] R.G. Carter, N. Soneda, K. Dohi, et al., J. Nucl. Mater. 298211 (2001).

[13] M.H. Mathon, A. Barbu, F. Dunstetter, et al., J. Nucl. Mater. 245224 (1997).

[14] U. Keiderling, A. Wiedenmann, Physica B 213\&214 895 (1995).

[15] O. Glatter, J. Appl. Cryst. 137 (1980). 
[16] G. Kostorz, in Physical Metallurgy, edited by R.W. Cahn and P. Haasen, (North-Holland, Amsterdam, 1996), Vol. 2, pp. 1115-1199.

[17] L. Koester, H. Rauch, E. Seymann, At. Data Nucl. Data Tabl. 4965 (1991).

[18] Y. Nagai, Z. Tang, M. Hassegawa, et al., Phys. Rev. B 63134110 (2001).

[19] J. Kocik, E. Keilova, J. Cizek, et al., J. Nicl. Mater. 30352 (2002).

[20] A. Ulbricht, F. Bergner, C. Dewhurst, et al., J. Nucl. Mater. 35327 (2006).

[21] A. Seeger, M. Rühle, Ann. Physik 11216 (1963).

[22] J. Böhmert, H.-W. Viehrig, A. Ulbricht, J. Nucl. Mater. 297251 (2001).

[23] A. Ulbricht, PhD Thesis, TU Bergakademie Freiberg, Germany, 2006.

[24] P. Auger, P. Pareige, S. Welzel, J-C. Van Duysen, J. Nucl. Mater. 280331 (2000).

[25] A. Takahashi, N. Soneda, S. Ishino, et al., Phys. Rev. B 67024104 (2003). 
Table 1. Composition of VVER440-type Sv10KhMFT weld material (wt.-\%).

$\begin{array}{lllllllllll}\mathrm{C} & \mathrm{Mn} & \mathrm{Si} & \mathrm{Cr} & \mathrm{Ni} & \mathrm{Mo} & \mathrm{V} & \mathrm{S} & \mathrm{P} & \mathrm{Cu} & \mathrm{Co} \\ 0.06 & 1.14 & 0.40 & 1.63 & 0.11 & 0.48 & 0.20 & 0.016 & 0.035 & 0.14 & 0.010\end{array}$


Table 2. Conditions of the samples for SANS experiments with $\Phi$ and $\varphi$ denoting neutron fluence and flux for neutron energies, $E>1 \mathrm{MeV}$ (to obtain values for neutron energies, $E>0.5 \mathrm{MeV}$, roughly multiply by 1.4).

\section{Designation} $\mathrm{U}$

I

IA

IAI-1

IAI-2

IAI-3

IAI-3A
Details

unirradiated

irradiated $\left(\Phi=2.5 \cdot 10^{19} \mathrm{~cm}^{-2}, \varphi=3.0 \cdot 10^{11} \mathrm{~cm}^{-2} \mathrm{~s}^{-1}\right)$ annealed $\left(475{ }^{\circ} \mathrm{C} / 100 \mathrm{~h}\right)$ after irradiation reirradiated $\left(\Phi=0.9 \cdot 10^{19} \mathrm{~cm}^{-2}, \varphi=3.0 \cdot 10^{11} \mathrm{~cm}^{-2} \mathrm{~s}^{-1}\right)$ reirradiated $\left(\Phi=1.8 \cdot 10^{19} \mathrm{~cm}^{-2}, \varphi=3.0 \cdot 10^{11} \mathrm{~cm}^{-2} \mathrm{~s}^{-1}\right)$ reirradiated $\left(\Phi=2.7 \cdot 10^{19} \mathrm{~cm}^{-2}, \varphi=3.0 \cdot 10^{11} \mathrm{~cm}^{-2} \mathrm{~s}^{-1}\right)$ annealed $\left(475^{\circ} \mathrm{C} / 100 \mathrm{~h}\right)$ after reirradiation 3 
Table 3. Measured total volume fraction, $c$, of non-magnetic structural defects in the size ranges specified and Vickers hardness, HV10, at load $98.1 \mathrm{~N}$.

Condition Volume fraction in specified size range, $c$ / vol.- \% * $0.5-2.5 \mathrm{~nm} \quad 2.5-4.5 \mathrm{~nm}$

$\mathrm{U}$

I

IA

IAI-1

IAI-2

IAI-3

IAI-3A
0.057

0.158

0.051

0.067

0.095

0.098

0.065

0.073

0.062

0.099

0.110

0.101

0.107

0.114
Vickers hardness, HV10 †

210

241

212

236

235

241

221

* typical error: 0.005

$\dagger$ mean value of 10 measurements, typical standard deviation: 5 
Table 4. Volume fraction, $\Delta c$, and A-ratio of irradiation-induced clusters and irradiation-induced hardness increase. For calculation of $\Delta c$, clusters are assumed to be non-magnetic.

\begin{tabular}{|c|c|c|c|c|c|c|}
\hline \multirow[t]{2}{*}{ Condition } & \multirow[t]{2}{*}{ Reference } & \multicolumn{2}{|c|}{$\begin{array}{l}\text { Volume fraction in specified } \\
\text { size range, } \Delta c / \text { vol.- } \%\end{array}$} & \multicolumn{2}{|c|}{ A-ratio } & \multirow[t]{2}{*}{$\begin{array}{l}\text { Hardness increase } \\
\Delta \mathrm{HV} 10\end{array}$} \\
\hline & & $0.5-2.5 \mathrm{~nm}$ & $2.5-4.5 \mathrm{~nm}$ & $0.5-2.5 \mathrm{~nm}$ & $2.5-4.5 \mathrm{~nm}$ & \\
\hline I & $\mathrm{U}$ & 0.102 & 0 & 1.56 & - & 31 \\
\hline IA & $\mathrm{U}$ & 0 & 0.026 & - & $\gtrsim 10$ & 2 \\
\hline IAI-1 & IA & 0.016 & 0.011 & 1.74 & - & 24 \\
\hline IAI-2 & IA & 0.044 & 0.002 & 1.88 & - & 23 \\
\hline IAI-3 & IA & 0.047 & 0.008 & 2.09 & - & 29 \\
\hline IAI-3A & IA & 0.014 & 0.015 & - & $\gtrsim 10$ & 9 \\
\hline \multicolumn{2}{|c|}{ Typical error: } & 0.007 & 0.007 & 0.1 & & 7 \\
\hline
\end{tabular}


Table 5. Irradiation, annealing and reirradiation conditions according to [10] for neutron energies, $E>0.5 \mathrm{MeV}$.

Designation Details

I irradiated, $\Phi=9.7 \cdot 10^{19} \mathrm{~cm}^{-2}, \varphi=1.5 \cdot 10^{11} \mathrm{~cm}^{-2} \mathrm{~s}^{-1}$

IA annealed $\left(475^{\circ} \mathrm{C} / 150 \mathrm{~h}\right)$ after irradiation

IAI-1 reirradiated, $\Phi=1.5 \cdot 10^{19} \mathrm{~cm}^{-2}, \varphi \approx 1.2 \cdot 10^{11} \mathrm{~cm}^{-2} \mathrm{~s}^{-1}$ 
Table 6. Composition (at.-\%) reported in [10] of clusters observed by 3DAP in neutron irradiated VVER440-type weld and calculated A-ratio.

$\begin{array}{llllllll}\text { Location of cluster } & \mathrm{Cu} & \mathrm{Mn} & \mathrm{Si} & \mathrm{Ni} & \mathrm{P} & \mathrm{Fe} & \text { A-ratio }\end{array}$

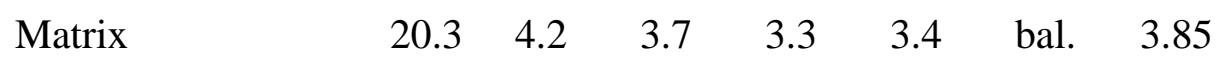

$\begin{array}{llllllll}\text { Dislocation line } & 34.8 & 1.6 & 3.5 & 5.6 & 3.3 & \text { bal. } & 7.90\end{array}$

3

6

7

9

10

11

12

13

14

15

16

17

18

19

20

21

22

23

24

25

26

27

28

29

30

31

32

33

34

35

36

37

38

39

40

41

42

43

44

45

46

47

48

49

50

51

52

53

54

55

56

57

58

59

60 
List of figures

Figure 1. Limiting cases for the reirradition behaviour of the brittle-to-ductile transition temperature as compared with the original irradiation, (a) horizontal shift, (b) vertical shift, (c) shift from the origin, (d) intermediate case.

Figure 2. Coherent neutron scattering cross section for unirradiated and irradiated conditions and after post-irradiation annealing; (a) total cross section, $\mathrm{d} \Sigma / \mathrm{d} \Omega_{\text {tot }}$, (b) nuclear cross section, $\mathrm{d} \Sigma / \mathrm{d} \Omega_{\text {nuc }}$, (c) magnetic cross section, $\mathrm{d} \Sigma / \mathrm{d} \Omega_{\text {mag. }}$.

Figure 3. Volume distribution function, $c_{R}$, for unirradiated and irradiated conditions and after post-irradiation annealing calculated by Fourier transformation of curves from figure 2c assuming non-magnetic scatterers.

Figure 4. Coherent neutron scattering cross section for annealed and reirradiated conditions and after post-irradiation annealing; (a) total cross section $\mathrm{d} \Sigma / \mathrm{d} \Omega_{\text {tot }}$, (b) nuclear cross section $\mathrm{d} \Sigma / \mathrm{d} \Omega_{\text {nuc }}$, (c) magnetic cross section $\mathrm{d} \Sigma / \mathrm{d} \Omega_{\text {mag. }}$.

Figure 5. Volume distribution function, $c_{R}$, for annealed and reirradiated conditions and after post-irradiation annealing calculated by Fourier transformation of curves from figure $4 \mathrm{c}$ assuming non-magnetic scatterers. 

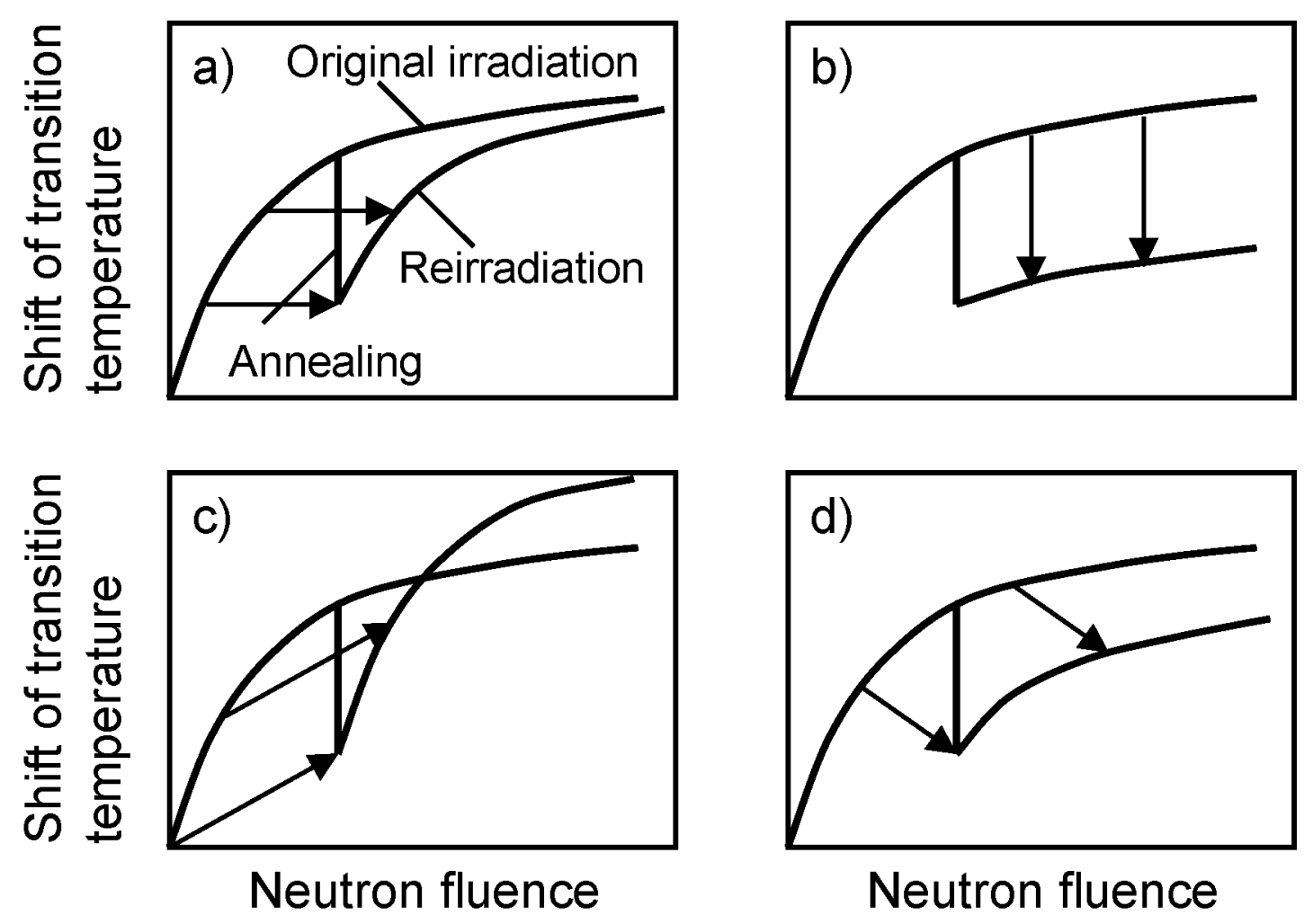

Figure 1 


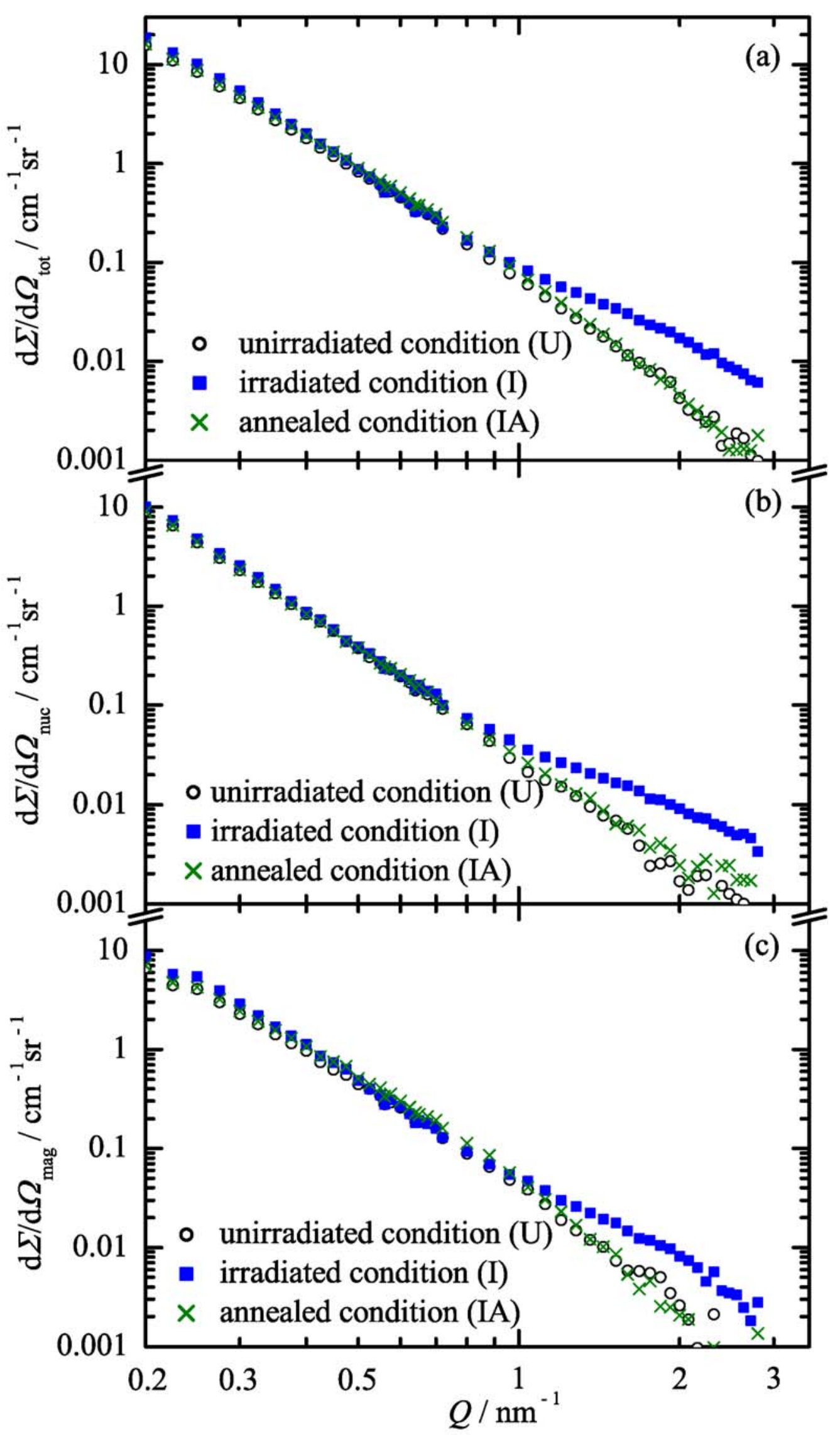

Figure 2 


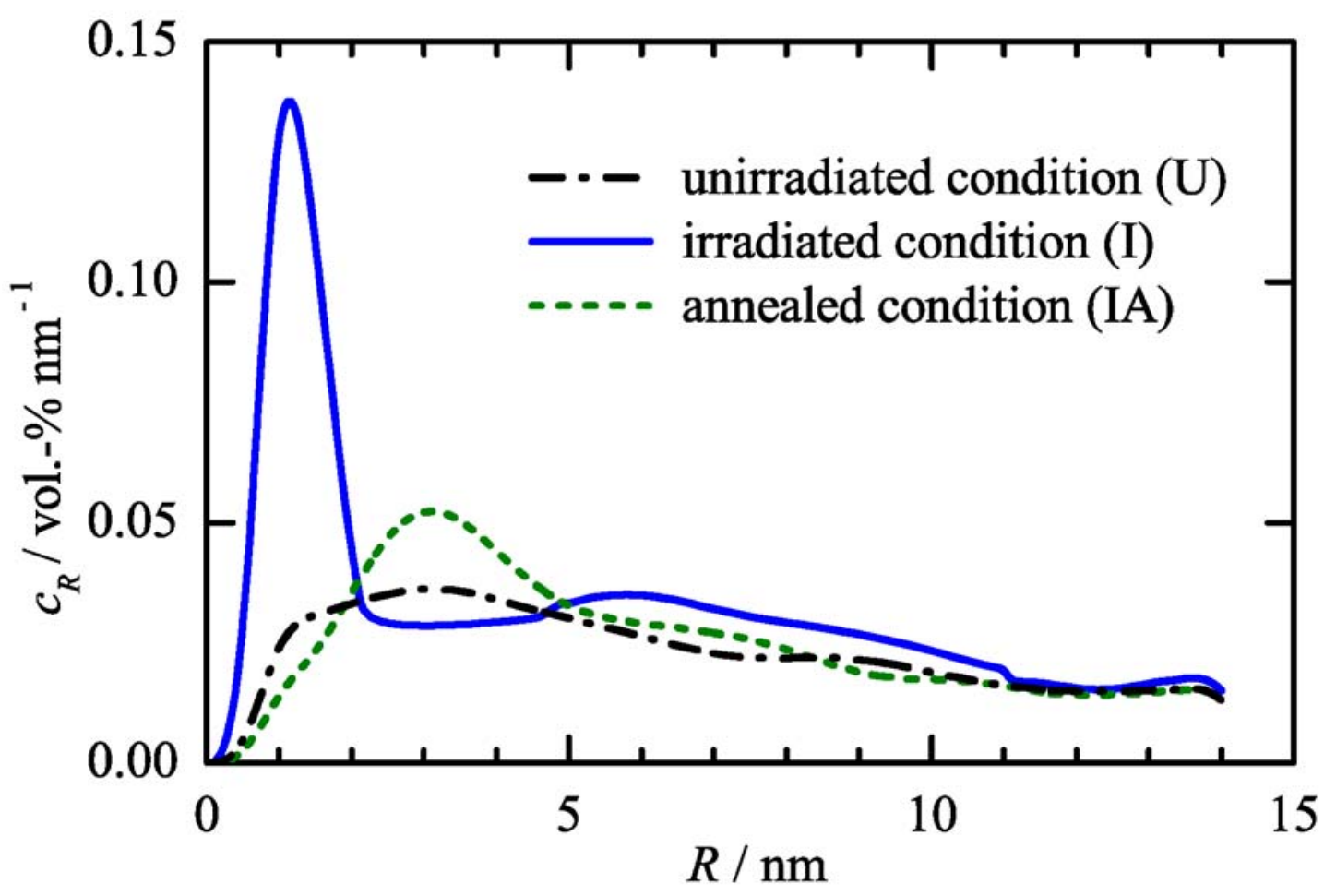

Figure 3 


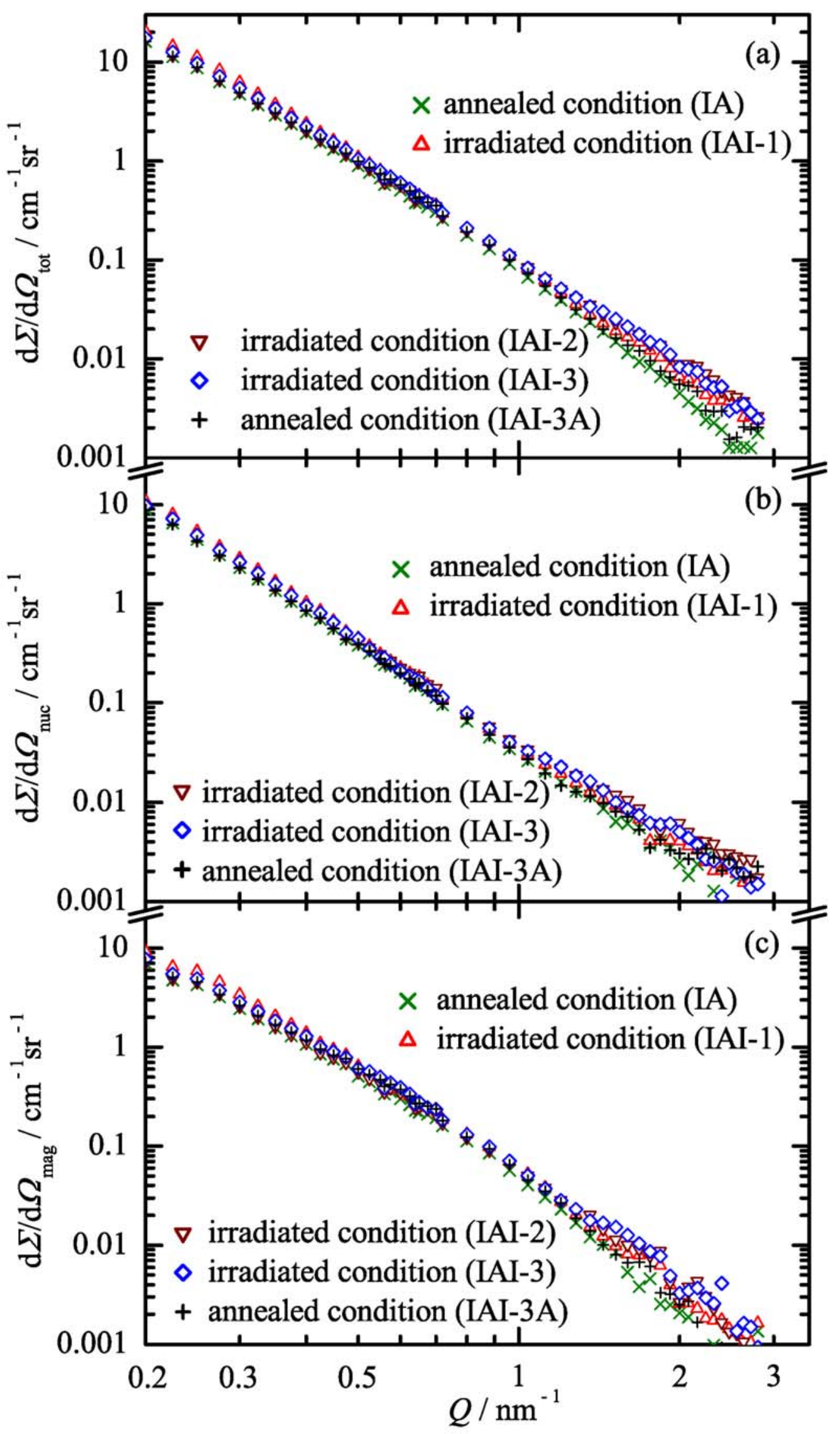

Figure 4 


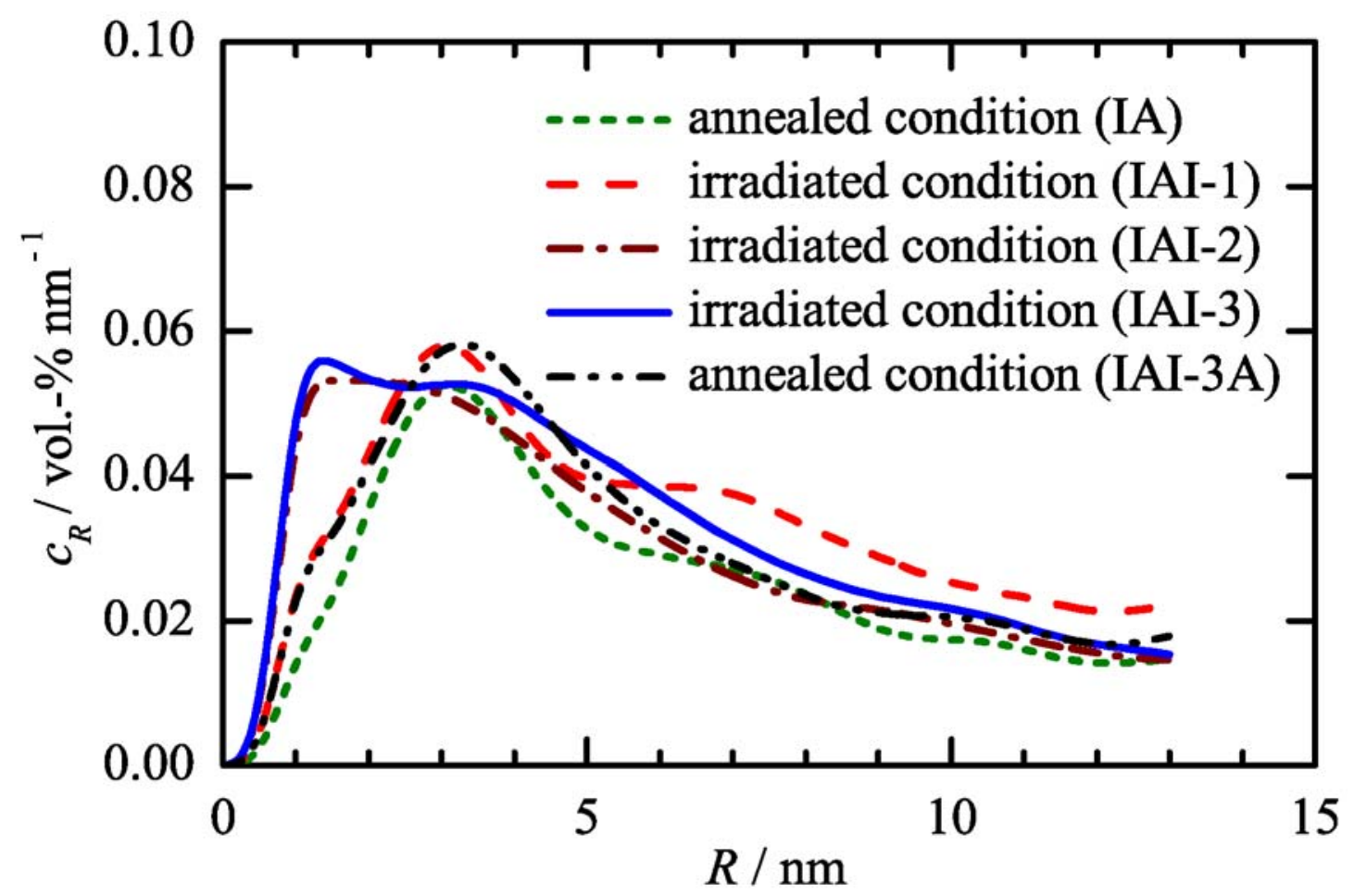

Figure 5 